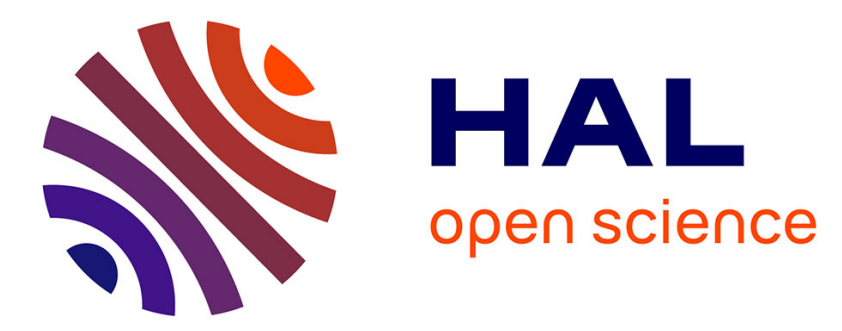

\title{
Breaking the law: unconventional strategies for antibody diversification
}

\author{
Alexia Kanyavuz, Annaelle Marey-Jarossay, Sébastien Lacroix-Desmazes, \\ Jordan Dimitrov
}

\section{- To cite this version:}

Alexia Kanyavuz, Annaelle Marey-Jarossay, Sébastien Lacroix-Desmazes, Jordan Dimitrov. Breaking the law: unconventional strategies for antibody diversification. Nature Reviews Immunology, In press, 10.1038/s41577-019-0126-7 . hal-02123078

\section{HAL Id: hal-02123078 https://hal.sorbonne-universite.fr/hal-02123078}

Submitted on 7 May 2019

HAL is a multi-disciplinary open access archive for the deposit and dissemination of scientific research documents, whether they are published or not. The documents may come from teaching and research institutions in France or abroad, or from public or private research centers.
L'archive ouverte pluridisciplinaire HAL, est destinée au dépôt et à la diffusion de documents scientifiques de niveau recherche, publiés ou non, émanant des établissements d'enseignement et de recherche français ou étrangers, des laboratoires publics ou privés. 


\title{
Breaking the law: unconventional strategies for antibody diversification
}

\author{
Alexia Kanyavuz ${ }^{1,2,3}$, Annaelle Marey-Jarossay ${ }^{1,2,3}$, Sébastien Lacroix-Desmazes ${ }^{1,2,3}$ and \\ Jordan D. Dimitrov ${ }^{1,2,3}$ \\ ${ }^{1}$ Sorbonne Universités, UPMC Univ Paris 06, UMR_S 1138, Centre de Recherche des \\ Cordeliers, F-75006, Paris, France; \\ ${ }^{2}$ INSERM, UMR_S 1138, Centre de Recherche des Cordeliers, F-75006, Paris, France; \\ ${ }^{3}$ Université Paris Descartes, Sorbonne Paris Cité, UMR_S 1138, Centre de Recherche des \\ Cordeliers, F-75006, Paris, France
}

\section{Correspondance to:}

Jordan D. Dimitrov, INSERM UMRS 1138, Centre de Recherche des Cordeliers, 75006 Paris, France.

Tel: +33144278206

Fax: +33144278194

E-mail: jordan.dimitrov@crc.jussieu.fr 


\begin{abstract}
Antibodies are an essential component of adaptive immunity. A typical antibody repertoire comprises an enormous diversity of antigen-binding specificities, which are generated by the genetic processes of recombination and mutation. Accumulating evidence suggests that the immune system can exploit additional strategies to diversify the repertoire of antigen specificities. These unconventional mechanisms exclusively target the antigen-binding sites of immunoglobulins and include the insertion of large amino acid sequences, post-translational modifications, conformational heterogeneity, and use of non-proteinaceous cofactor molecules. Here, we describe the different unconventional routes for diversification of antibody specificities. Furthermore, we highlight how the immune system has a much greater level of adaptability and plasticity than previously anticipated, which goes far beyond that encoded in the genome or generated by the acquisition of somatic mutations.
\end{abstract}




\section{[H1] Introduction}

Antibodies are the major component of humoral adaptive immunity to pathogens. They are produced by plasma cells, which derive from $\mathrm{B}$ cells that express on their surface the membrane-bound form of the antibody, that is, the B cell receptor (BCR). Antibodies first appeared in evolution in cartilaginous fishes more than 500 million years ago ${ }^{1}$. The prototypic antibody molecule (IgG) is a congregation of four polypeptide chains; two identical heavy $(\mathrm{H})$ and two identical light (L) Ig chains. The N-terminal regions of heavy and light chains are characterized by extensive variability in the amino acid sequence. Accordingly, these parts of the molecule are referred to as variable (V) regions and are responsible for recognition of the antigen (the structural organization of V regions is described in BOX 1). In contrast, the Cterminal part of the Ig molecule, referred to as the constant region, is less variable and differs only between distinct Ig classes and subclasses. This particular structural organization allows antibodies to bridge the process of molecular recognition of antigen with initiation of destructive innate immune mechanisms such as activation of the complement system, phagocytosis and degranulation ${ }^{2}$.

Adaptive immunity relies on sophisticated genetic mechanisms to create the diversity of antibody V regions. These mechanisms take place during B cell development in the bone marrow and upon encounter of antigen in the periphery. Two distinct processes contribute to the genetic diversification of $\mathrm{V}$ regions: $\mathrm{V}(\mathrm{D}) \mathrm{J}$ recombination and somatic hypermutation (BOX 2). Theoretically, under physiological conditions the human immune system can generate BCRs with $10^{26}$ distinct sequences ${ }^{3,4}$, an astronomical number that is far greater than the calculated number of all B cell clones that can be generated during the lifespan of a healthy human (estimated to be $\left.4 \times 10^{14}\right)^{3}$. The recent advent of technologies that allow highthroughput sequencing of the entire human B cell repertoire ${ }^{5,6}$ as well as isolation and characterization of human monoclonal antibodies ${ }^{7}, 8$ has contributed to the identification and 
better characterization of some alternative or 'unconventional' mechanisms that contribute to diversification of the antibody repertoire. For example, antibodies have been reported to integrate non-immunoglobulin proteins as part of their binding sites and use these proteins for specific binding to target antigens. In addition, novel antigen-binding specificities can be generated by post-translational modifications, extensive flexibility in the structural dynamics of the antigen-binding site, or the use of non-protein cofactor molecules for antigen recognition. Notably, some of unconventional strategies of antibody diversification are frequently elicited in response to infections with highly mutable pathogens.

In this Review, we classify the different unconventional mechanisms for antibody diversification and describe the molecular basis and putative biological roles of each mechanism. Finally, we discuss the broader implications of these unconventional pathways of generating antibody diversity.

\section{[H1] Unconventional antibody diversification}

In addition to the conventional genetic mechanisms used to generate antibody diversity, the immune system uses several alternative strategies to broaden the antibody repertoire. Below, we group these strategies into four distinct categories, based on the molecular mechanism involved; one) insertion of non-immunoglobulin sequences in the variable region; two) posttranslational modification of the variable region; three) conformational heterogeneity of the antigen-binding site; four) use of non-protein cofactors for antigen recognition (metal ions or haem).

\section{[H2] Non-Ig V region insertions}


Recent studies have shown that sequences from non-immunoglobulin genes can be inserted into the V regions of Igs. In addition, we discuss the addition or deletion of short nucleotide sequences (known as 'indels') into $\mathrm{V}$ region genes during somatic mutation.

\section{[H3] Insertion of long amino acid sequences into $V$ regions.}

The infection of red blood cells with Plasmodium falciparum results in the expression of parasite-derived antigens on cellular surfaces. After screening hundreds of plasma samples from adults living in malaria endemic regions in Kenya, Tan et al. identified two donors with antibodies that have broad reactivity towards antigens from eight different isolates of $P$. falciparum displayed at the surface of the infected erythrocytes ${ }^{9}$. B cells from these donors were immortalized and the sequence of the broadly reactive antibodies analyzed. Surprisingly, it was found that the $\mathrm{V}_{\mathrm{H}}$ of these antibodies contained a large non-Ig fragment from chromosome 19 between the $\mathrm{V}$ and DJ segments in the CDR3H region ${ }^{9}$. This foreign segment encodes 98 amino acids of leukocyte-associated immunoglobulin-like receptor 1 (LAIR1), an Ig superfamily inhibitory receptor that normally binds collagen ${ }^{10}$. Elegant experiments showed that antibodies directly use LAIR1 protein for the recognition of malarial antigens 9 . Interestingly, LAIR1 incorporated in the $\mathrm{V}_{\mathrm{H}}$ region carries a significant number of somatic mutations that ablates the binding to collagen, but confers increased affinity for $P$. falciparum antigens. Mass spectrometry identified the target antigens for LAIR1 as belonging to members of the repetitive interspersed families of polypeptides (RIFIN) family — the largest family of $P$. falciparum antigens displayed on infected erythrocytes ${ }^{9}$. Furthermore, X-ray crystallography analyses ${ }^{11}$ revealed that LAIR1 is well folded and is displayed on the tip of V region in an appropriate configuration for interaction with antigen (FIG. 1A).

In another study, the same team evaluated the frequency of broadly reactive antiRIFIN antibodies by screening two large cohorts of Plasmodium-exposed individuals in 
Tanzania and $\mathrm{Mali}^{12}$. It was found that 5 to $10 \%$ of these malarial parasite-exposed individuals expressed LAIR1-containing antibodies, whereas such antibodies were not detectable in cohorts of non-exposed European donors. Sequence analyses of cDNA and gDNA from $\mathrm{B}$ cell clones isolated from donors with LAIR1-containing antibodies demonstrated that the insertions of the LAIR1 sequence can occur not only between the V and DJ gene segments, but occasionally between the $\mathrm{V}$ domain and the first constant domain (CH1) of the heavy Ig chain ${ }^{12}$. This allows the B cell clone to produce an antibody through alternative splicing either without or with a functional LAIR1 protein insert in the elbow region, thus conferring the antibody with a second antigen-binding specificity. In addition, a B cell clone from another donor produced a LAIR1-containing camel-like antibody that lacked the $\mathrm{V}_{\mathrm{H}}$ and $\mathrm{C}_{\mathrm{H} 1}$ regions as well as the whole light-chain.

Importantly, deep-sequencing analyses of healthy European donors revealed a higher than expected prevalence of memory B cells with sequence insertions of 100-1000 nucleotides from other chromosomes in the elbow region ${ }^{12}$. This finding suggests that antibodies can use this unusual strategy for diversification of their specificities against other pathogens as well. The molecular mechanisms governing the interchromosomal DNA transposition in B cells, which leads to insertion of entire proteins in the antigen-binding site or next to it, are not yet well understood. One can hypothesize that insertion of LAIR1 into the variable region of antibodies involves the same molecular machinery that is responsible for the diversification of the immunoglobulin genes, that is, the recombination activating genes (RAG1 and RAG2) and activation-induced cytidine deaminase (AID). Notably, malaria infection is associated with a marked genomic instability and AID-mediated translocations between different chromosomes in $\mathrm{B}$ cells ${ }^{13}$. The increased frequency of chromosomal translocations may facilitate LAIR1 incorporation into $\mathrm{V}$ regions of antibodies. The $\mathrm{B}$ cells 
expressing such antibodies might be further positively selected and sustained since LAIR1 protein provides selective advantage for broad recognition of different strains of the pathogen.

\section{[H3] Indels: in frame insertions and deletions.}

During affinity maturation an unconventional mechanism of generation of diversity in the $\mathrm{V}$ genes of the BCR may take place: the in-frame insertion or deletions of nucleotide sequences (referred to as indels) in V genes (FIG. 1B). The frequency, localization and mechanisms of indel formation have been investigated by deep-sequencing analysis of $\mathrm{V}$ region genes of human B cells. Indels were estimated to be present in approximately $2 \%$ of circulating B cells from healthy individuals ${ }^{14}$. The frequency of indels is considerably higher in memory B cell subsets compared with naive B cells. The size of in-frame insertions or deletions range from 3 to 33 nucleotides $^{14,15}$, but most $\mathrm{V}$ regions contain short indels. The insertion or deletion of nucleotide sequences is mediated by the same machinery that is responsible for the introduction of point mutations during the affinity maturation process ${ }^{15}$. Indeed, the expression of AID is required and sufficient for both in vivo and in vitro formation of indels ${ }^{16}$. Importantly, indels and their proximal regions can be further modified by point mutations introduced by AID. The indels are most frequently located in the antigen-binding sites of antibodies, predominantly in the CDR1 and CDR2 loops of the $\mathrm{V}$ regions of both $\mathrm{H}$ and $\mathrm{L}$ chains. This explains their potential for remodeling the binding specificity of antibodies ${ }^{14,16}$. Indels can also be introduced in framework regions of the V domain, especially in the FR3 of the $\mathrm{H}$ chain ${ }^{17}$. Long insertions are more frequent in CDRs, whereas long deletions are mostly located in the framework regions ${ }^{14}$. This phenomenon may be due to the restricted size of CDRs that cannot tolerate long deletions. The presence of indels induces considerable reconfiguration of the CDRs loops and/or surrounding regions, leading to a dramatic impact on the antigen-binding specificity, affinity and functional activity of antibodies ${ }^{17,18}$. 
Indels may have an important contribution to antibody-mediated neutralization of pathogens with a high antigenic heterogeneity. Indeed, the frequency of insertions in $\mathrm{V}$ genes of B cells from HIV-1-infected individuals is significantly increased as compared to that of B cells isolated from healthy humans ${ }^{17}$. An elevated frequency of insertions was, however, not demonstrated in the case of B cells from patients chronically infected with Epstein-Barr virus and/or cytomegalovirus ${ }^{17}$. Notably, a considerable fraction $(40 \%)$ of the most potent and broadly neutralizing antibodies (bNAbs) for HIV contains indels ${ }^{17}$. Insertions in HIV-1 bNAbs are directly involved in the establishment of contacts with antigens ${ }^{19}$. They also modulate the antigen-binding kinetics of bNAbs and endow antibodies with broad HIV-1 neutralization potential.

The significance of indels was elegantly demonstrated in the study of the influenzaneutralizing human monoclonal antibody $2 \mathrm{D} 1^{18}$. 2D1 contains an insertion of three amino acids in the region between FR3 and CDR H2. The deletion of the indel from the antibody led to a considerable decrease in binding affinity for hemagglutinin, in neutralization potency and in therapeutic activity in vivo. Structural analyses revealed that the presence of an insertion in $2 \mathrm{D} 1$ results in the reconfiguration of the paratope in such a way that there is removal of a steric hindrance between the $\mathrm{CDR} \mathrm{H} 2$ and a loop from the hemagglutinin molecule ${ }^{18}$. Conversely, the indel-deleted variant acquired a canonical configuration of the CDR H1 that was not suitable for potent neutralization of the influenza virus.

In conclusion, although the formation of indels is not a frequent phenomenon, it brings an additional level of diversity to antibodies, thus allowing them to adapt to antigen surfaces that are difficult to be recognized by conventional antibodies. Especially in the case of infection with HIV-1 where their frequency is remarkably increased, indels may allow the immune repertoires to accommodate virus antigenic variability. 


\section{[H2] Post-translational modifications}

Post-translational modifications of proteins represent covalent conjugation of non-proteinous groups to the polypeptide chains. These modifications modulate the functional activity and physicochemical properties of many intracellular and extracellular proteins. There are many diverse types of post-translational modifications, the most prominent being glycosylation, phosphorylation, lipidation and sulphation. Igs, as any proteins, are subjected to posttranslational modifications. A typical modification is glycosylation of Asn297 on the heavy chain of human IgG molcules. The N-glycans added to the constant region have an important impact on the effector functions of antibodies (reviewed in Ref. ${ }^{20}$ ). In addition to constant region modification, a fraction of human antibodies can undergo post-translational changes that are localized in the $\mathrm{V}$ region and therefore might directly influence antigen binding. Thus, tyrosine o-sulphation in $\mathrm{CDR} \mathrm{H} 3$ or glycosylation in $\mathrm{V}$ regions contributes to the diversification of antigen-binding specificities of antibodies by tailoring the chemistry and topology of the antigen-binding region (FIG. 2).

\section{[H3] Tyrosine sulphation.}

O-sulphation of tyrosine is a post-translational modification present in more than 200 human proteins. It affects mostly secretory and membrane-bound proteins, with examples including coagulation factors and G-protein coupled receptors ${ }^{21}$. The sulphation of tyrosine residues is enzymatically catalysed by membrane-associated tyrosylprotein sulphotransferases that are localized in the Golgi apparatus ${ }^{22}$. For some human antibodies, sulphation critically shapes their binding specificity; one such example is provided by patient-derived anti-HIV-1 antibodies, as described below. 
A group of HIV-1-specific antibodies recognizes an epitope on the viral envelope protein complex that is only displayed upon interaction of viral gp120 with CD4 on host cells. Accordingly, these antibodies are referred to as CD4-induced (CD4i) antibodies. Characterization of CD4i monoclonal antibodies isolated from HIV-1-infected patients revealed a peculiar feature of some of these antibodies - they have a sulphotyrosine in their $\mathrm{CDR}-\mathrm{H}^{23}{ }^{24}$. Most of the human $\mathrm{CD} 4 \mathrm{i}$ antibodies are encoded by a restricted set of $\mathrm{V}$ region genes belonging to the $\mathrm{V}_{\mathrm{H}} 1-69$ and $\mathrm{V}_{\mathrm{H}} 1-24$ families ${ }^{23}$. Usually these antibodies have long CDR H3 loops that are rich in tyrosines interspersed between acidic amino acids, a preferential target pattern for tyrosylprotein sulphotransferases. The presence of tyrosine sulphation was demonstrated to be critical for binding to gp120 and for virus neutralization by some CD4i monoclonal antibodies. Thus, mutation of tyrosine to phenylalanine or silencing of tyrosylprotein sulphotransferases in antibody-expressing cells resulted in complete abrogation of gp120 binding and HIV-1 neutralization by the CD4i antibody $412 \mathrm{~d}^{23}$. As a whole, antibodies containing sulphotyrosine neutralize HIV-1 more potently than antibodies directed to the same region on gp120 but lacking this post-translational modification.

Structural analyses of the CD4i monoclonal antibodies 47e, E51 and 412d demonstrated that sulphotyrosine residues are located on the tip of protruding and highly disordered CDR H3 loops ${ }^{24}$. The antigen-binding sites have a strong negative charge, owing to the sulphate groups. Two of the investigated antibodies have a single sulphotyrosine and one has two sulphotyrosine residues in CDR $3^{24}$. The binding site for gp120 on the HIV-1 co-receptor CCR5 overlaps with the epitope of CD4i antibodies. Notably, a region of CCR5 responsible for the binding of gp120 to CCR5 also contains a sulphotyrosine ${ }^{25}$. Indeed, a peptide from the CCR5 co-receptor, containing the sulphotyrosine, competes with the monoclonal antibodies for binding to the gp120-CD4 complex ${ }^{23}$. Structural analyses revealed that the sulphotyrosine residues of CCR5 and the CD4i antibody $412 \mathrm{~d}$ adopt an almost 
identical configuration while binding to the same binding site on the gp120 molecule ${ }^{26}$. Thus, both sulphotyrosines are accommodated in a deep pocket with hydrophobic surrounding and cationic base; the sulphate group of tyrosine establishes numerous non-covalent contacts with residues from the antigen. These results suggest that the presence of sulphotyrosines in the CDR H3 of CD4i antibodies confers a molecular mimicry whereby antibodies bind the virus in a manner analogous to the binding of the co-receptor molecule to the virus. Accordingly, the antibodies containing sulphotyrosines in their CDR H3 loops are efficient at neutralizing CCR5-tropic strains but fail to neutralize HIV-1 strains that use the CXCR4 coreceptor for infection of cells ${ }^{23}$.

Tyrosine sulphation has also been described in another class of HIV-1-neutralizing human antibodies. The epitopes of the antibodies 2909, PG9 and PG16 overlap with V2 and V3 loops on gp120. Structural analysis revealed that these antibodies contain sulphated tyrosines in their CDR H3 loops ${ }^{27,28}$. Similarly to what was seen with CD4i antibodies, the removal of sulphotyrosine from strain-specific antibody 2909 by mutation to phenylalanine resulted in loss of its neutralization potential ${ }^{28}$. Moreover, the removal of sulphotyrosines from the bNAbs PG9 and PG16 significantly reduced their HIV-1-neutralization potency ${ }^{27}$.

In conclusion, some antibodies show sulphation of tyrosines in their hypervariable regions and this post-translational modification can help them to bind and neutralize HIV-1. The unique chemical reactivity of the sulphate groups endows the antibodies with novel binding features. It is noteworthy that these results infer that the humoral immune response can produce antibodies that mimic recognition tactics used by other receptors.

[H3] N-glycosylation of the variable region. 
In healthy humans, 15 to $25 \%$ of IgG antibodies have N-linked glycan structures in their $\mathrm{V}_{\mathrm{H}}$ or $\mathrm{V}_{\mathrm{L}}$ regions ${ }^{29}$. The frequency of antibodies with $\mathrm{V}$-bound glycan structures can increase considerably in some pathological conditions, such as rheumatoid arthritis and Sjorgen's syndrome ${ }^{29-32}$. Interestingly, human antibody repertoires encoded by naive B cells are almost devoid of Fab-bound glycans. The glycosylation sites are virtually absent from the germline sequences and are introduced in $\mathrm{V}$ region genes predominantly as a consequence of the somatic hypermutation process ${ }^{29,33,34}$. The hot spots for mutations leading to glycosylation in $\mathrm{V}$ regions are predominantly located within the CDR loops or in a close proximity ${ }^{34}$. Analyses of Fab glycosylation of antibodies isolated from healthy donors revealed that the prevalence of N-glycosylation of the $\mathrm{V}$ regions differs among IgG subclasses. The most frequently glycosylated human IgG is the IgG4 subclass with $44 \%$ of the molecules having N-linked glycans. Among the other subclasses, the N-glycosylation of V region occurs between 11 and $15 \%$. Notably, the frequency of V-glycosylated antibodies also depends on the target antigen and may change depending on the physiopathological state. Thus, a majority of autoantibodies (80-100\%) recognizing citrullinated proteins in patients with rheumatoid arthritis contain Fab-bound glycans ${ }^{31,32,34}$

The most frequent glycan structure attached to $\mathrm{V}$ regions is a complex biantennary type, enriched in terminal 2,6-linked sialic acids. In contrast to the N-glycan attached to the Asn297 of the constant region, V region glycans are considerably more exposed on the surface of the IgG molecule $\mathrm{l}^{35,36}$. The predominant localization of N-glycosylation sites in the antigen-binding site and the high exposure of the glycan suggest that this post-translational modification can influence the antigen-binding specificity of the antibodies. Indeed, the study of an anti-dextran monoclonal antibody, containing an N-glycan bound to the CDR H2, showed that removal of this post-translational modification leads to a 15 -fold decrease in the binding affinity of the antibody ${ }^{35}$. A similar decrease in binding affinity was observed after 
specific removal of sialic acid from the $\mathrm{V}$ region of an $\mathrm{IgG}$ specific for the gonadotropinreleasing hormone ${ }^{37}$. Another study has shown that the human polyreactive antibody CBGA1 possesses complex N-glycans consisting of biantennary and tetraantennary glycans. These glycans are rich in sialic acid (which constitutes approximately $18.2 \%$ of glycan composition) and consequently show an overall negative charge. Removal of the glycan of CBGA1 using specific inhibitors of the cellular glycosylation machinery resulted in an almost complete abrogation of binding to its target antigens - namely, tetanus toxoid, diphtheria toxoid and $\mathrm{dsDNA}^{36}$. This result points to an intriguing case where a complex glycan structure attached to a $\mathrm{V}$ region mediates the antigen-binding polyreactivity of an antibody.

In a recent investigation, a panel of Fab-glycosylated human IgG monoclonal antibodies was mutated at the glycosylation sites back to the germ-line residues. In most of the IgGs, mutations abrogating the glycosylation of the $\mathrm{V}$ region resulted in a significant decrease in their binding affinity for the target antigen ${ }^{34}$. Another study demonstrated that a human IgG alloantibody (LE2E9) that neutralizes the pro-coagulant activity of factor VIII, has a complex glycan structure bound to $\mathrm{CDR} \mathrm{H}^{38}$. While the removal of the V-linked glycan by mutagenesis did not affect the antibody's binding affinity for factor VIII, it significantly decreased its neutralizing activity. Moreover, although the wild-type LE2E9 antibody efficiently blocked the binding of factor VIII to its chaperone — von Willebrand factor - the aglycosylated LE2E9 antibody lost this activity. This suggests that the glycan in the LE2E9 antibody blocks the interaction of factor VIII with von Willebrand factor through steric hindrance ${ }^{38}$. These findings point to the importance of $\mathrm{V}$ region glycans for modulating the functional activity of antibodies independently of the antigen-binding properties of the antibody.

Addition of N-glycans has also been used for the rational engineering of antibodies. Thus, the introduction of N-linked glycans to the binding site of an anti-CD4 humanized 
monoclonal IgG, ibalizumab, resulted in a dramatic augmentation of breadth and potency of HIV-1 neutralization ${ }^{39}$. Of note, the introduction of glycan structures in the antigen-binding sites of antibodies with defined specificity has also been shown to decrease antigen-binding polyreactivity or to completely inhibit the interaction with target antigens ${ }^{40,41}$.

Collectively, these findings suggest that V-region linked carbohydrates contribute to the diversification of the specificity of antibodies. The molecular mechanisms underlying the contribution of N-linked glycans to antigen binding are not elucidated as yet. However, one can expect that carbohydrates enhance the chemical diversity of paratopes by providing numerous additional possibilities for non-covalent contacts and enriching the shape complexity. Moreover, the high degree of conformational dynamics that characterizes glycans may contribute to an extension of the repertoire of configurations of the antigen-binding sites, thus diversifying the binding specificities.

\section{[H2] Conformational heterogeneity}

Every protein has a certain degree of conformational dynamics ranging from infinitesimal structural fluctuations, which are typical for rigid proteins, to global structural dynamics, which are characteristic of intrinsically disordered proteins ${ }^{42,}{ }^{43}$. Likewise, the extensive heterogeneity of the amino acid sequences of $\mathrm{V}$ regions results in antibodies with different degrees of flexibility in their antigen-binding sites. As result a single antigen-binding site can acquire multiple configurations, thus resulting in binding to distinct antigens and

diversification of antigen-binding specificity ${ }^{44,45}$. In rare cases, antibodies have also been reported to reconfigure the global structure of the Fab, thus achieving unconventional recognition of carbohydrate antigens (discussed below). 
[H3] Conformational dynamics of the V region.

The conformational flexibility of an antibody plays a key role in recognition of its cognate antigen. Antibodies with pliable antigen-binding sites are capable of binding to many structurally unrelated antigens ${ }^{46-49}$, and are defined as polyreactive, polyspecific or promiscuous. Antibodies with highly flexible binding sites can exploit larger conformational space, thus adapting to molecular features of different targets. Hence, one sequence of a $\mathrm{V}$ region with its plurality of configurations can accommodate numerous different antigens. This can lead to an enormous broadening of the array of antigenic targets potentially recognized by the humoral immune repertoire.

Different structural and biophysical analyses demonstrated that antibodies with $\mathrm{V}$ regions encoded by germ-line sequences exhibit a generally higher degree of conformational dynamics in their antigen-binding sites ${ }^{46,50-56}$. These studies have however limitations as they usually only encompass a small number of antibodies that target (except in the study of Schmidt et $\mathrm{al}^{56}$ ) low molecular weight compounds (haptens), peptides or carbohydrates. A recent computational study comprehensively analysed the molecular dynamics of the flexibility of the CDR $\mathrm{H} 3$ as a function of affinity maturation in the case of thousands of human antibody sequences. The results reveal that there is no straightforward correlation between the degree of molecular flexibility and the level of somatic mutations introduced in the $\mathrm{V}$ regions. Thus, the accumulation of somatic mutations may result either in the rigidification or, on the contrary, in an increase of the structural dynamics of the $\mathrm{CDR} \mathrm{H} 3^{57}$. This was further confirmed by an investigation focused on effect of affinity maturation on the flexibility of antigen-binding site of different HIV-1 bNAbs ${ }^{58}$ and by the observation that affinity maturation resulted in an increase of the plasticity of an antibody targeting hen egg lysozyme $^{59}$. 
The diversification of binding specificities through conformational dynamics may be important for antibodies that target highly heterogeneous pathogens, such as HIV-1. Binding analyses demonstrated that many of bNAbs are highly promiscuous and recognize many unrelated antigens apart from the HIV-1 Env proteins ${ }^{8,}$ 60-62. It is noteworthy that these antibodies are often characterized by high numbers of somatic mutations. Recent results suggested that enhanced structural dynamics might directly contribute to the accommodation of antigenic variability and neutralization of distinct strains of HIV $-1{ }^{63}$. In addition, in the case of two monoclonal bNAbs, 3BNC60 and 3BNC117, accumulation of a large number of somatic mutations that affect the framework regions results in acquisition of a prominent molecular flexibility in the $\mathrm{V}_{\mathrm{H}}$ beta-sheet framework region. This extraordinary flexibility directly contributes to the binding to highly heterogeneous epitopes on gp120 from distinct HIV-1 strains ${ }^{19}$, resulting in potent and broad neutralization of the virus.

Two structural models of molecular dynamics account for the binding promiscuity of $\operatorname{antibodies}^{44,64}$. The 'induced-fit' model (also known as the Koshland model), that was initially developed to describe enzyme-substrate interactions, stipulates that structural changes in the antigen-binding site that take place during the molecular recognition process, result in adaptation to the target molecule ${ }^{65}$. This model assumes that a higher level of pliability of the V region allows adaptation to a larger set of unrelated antigens. Since a large range of conformational adaptations commonly occurs in all antibody-antigen interactions, the induced-fit model is not an 'unconventional strategy' for diversification of antibody specificities per se. Alternatively, the conformational selection model proposes that, in the absence of antigen, the antigen-binding sites of a given antibody concomitantly exist in distinct configurations (isomers) (FIG. 3A). Each isomer has the capacity to recognize different molecular targets. Depending on the available antigen, a given isomer will be preferentially engaged $^{65}$. Kinetic and structural evidence has been provided for the existence 
of this unconventional mechanism of diversification of antibody specificities ${ }^{66,67}$. For instance, structural analyses of the mouse monoclonal IgE clone SPE7, demonstrated a dramatic and diverse reconfiguration of the antigen-binding site in the absence of antigen ${ }^{68}$. In one of the configurations, the binding site of SPE7 forms a deep and narrow pocket, which is appropriate for the recognition of haptens. Another configuration of SPE7 forms a large flatshaped antigen-binding site, which is suitable for the recognition of protein antigens (FIG. 3A). Notably, kinetic studies of SPE7 revealed that the binding promiscuity of this antibody is driven by the simultaneous implication of induced-fit and conformational isomerism ${ }^{67,68}$.

More than $20 \%$ of $\mathrm{B}$ cells from healthy individuals express BCRs with prominent antigen-binding polyreactivity ${ }^{48,69-72}$. This frequency may be further increased upon some viral or bacterial infections ${ }^{62,73-76}$. The proportion of polyreactive antibodies that use conformational isomerism for diversification of their antigen-binding specificities remains unknown. However, it is highly probable that this mechanism represents a predominant way for achievement of binding promiscuity of antibodies, as it has been shown for other proteins $^{65,77}$.

\section{[H3] Global reconfiguration of Fab.}

Another unorthodox strategy to achieve diversification (FIG. 3B) of the antigen-binding specificity of antibodies, based on structural changes in the molecule, is exploited by a human HIV-1 bNAb called $2 \mathrm{G} 12^{78}$. This antibody recognizes mannose residues displayed on the dense glycan cluster on surface of gp120. The structural analyses of $2 \mathrm{G} 12$ revealed an unconventional configuration of its antigen-binding site. Thus, the $\mathrm{V}_{\mathrm{H}}$ domains of the antibody are swapped leading to their direct contact. This dramatic structural reconfiguration results in formation of an extended binding surface, consisting of $\mathrm{V}_{\mathrm{L}}: \mathrm{V}_{\mathrm{H}}: \mathrm{V}_{\mathrm{H}}: \mathrm{V}_{\mathrm{L}}$ domains (instead of what is seen in classical antibodies). The binding surface exhibits four antigen- 
binding sites - two primary sites and two sites that are formed as a consequence of $\mathrm{V}_{\mathrm{H}}$ domain swapping. The structural reconfiguration of $2 \mathrm{G} 12$ is due to a number of somatic mutations that curtail the non-covalent interactions that generally hold $\mathrm{V}_{\mathrm{H}}: \mathrm{V}_{\mathrm{L}}$ together, modify the elbow between $V_{H}$ and $C_{H 1}$ and introduce complementarity throughout the $V_{H}: V_{H}$ surface $^{78}$. This unique architecture enables 2 G12 to recognize a cluster of dense oligomannose carbohydrates on gp120 with an affinity in the $\mathrm{nM}$ range ${ }^{79}$. In the case of the canonical antigen-binding site of Igs, such recognition is prohibited due to steric constrains.

The binding site of $2 \mathrm{G} 12$ on gp120 overlaps with binding sites of other HIV-1 bNAbs (PGT121/10-1074 family). These antibodies however use conventional mechanisms for antigen recognition. The difference between $2 \mathrm{G} 12$ and other antibodies targeting the same neutralization site on gp120 is that the latter contact both the protein and carbohydrate components of gp $120^{80}$, whereas the epitope of $2 \mathrm{G} 12$ consist only of glycan. It is tempting to speculate that the selective pressure for high avidity recognition of the glycan epitope on gp120 resulted in an untypical organization of the binding site of $2 \mathrm{G} 12$.

A recent study revealed yet another stratagem that increases the avidity for repetitive epitopes on pathogens ${ }^{81}$. Antibodies targeting the circumsporozoite protein (anti-NANP antibodies) of Plasmodium falciparum can provide protection against malaria infection. Interestingly, it was demonstrated that some of the anti-NANP human antibodies acquire a set of somatic mutations that facilitate the self ('homotypic') association of two V regions during the recognition of the antigen ${ }^{81}$. Such a homotypic binding of $\mathrm{V}$ regions contributes to augmentation in binding avidity, thus resulting in efficient recognition of repetitive epitopes of the antigen. At the level of the BCR, the homotypic interaction of different receptors induced by circumsporozoite antigen results in potent $\mathrm{B}$ cell activation ${ }^{81}$. In contrast to the mechanism used by $2 \mathrm{G} 12$, the $\mathrm{V}$ regions of anti-NANP antibodies that associate together and create a peculiar antigen-binding surface belong to distinct antibody molecules. 


\section{[H2] Use of non-protein cofactors}

Many prokaryotic and eukaryotic proteins use different cofactors, ranging from metal ions to large organic compounds, to extend their functional activities. For example, cofactors enable enzymes to catalyze multifarious types of reactions, which would be impossible with the mere use of amino acids from the polypeptide chain. Interestingly, some antibodies have been reported to exploit non-protein cofactors for the diversification of their antigen-binding specificities (FIG. 4). This part of the review focuses on the 'inherent' tendency of some antibodies to use this diversification tactic.

[H3] Use of metal ions.

The antibody Q425 is a mouse monoclonal IgG that specifically recognizes an epitope in the domain 3 of the CD4 receptor and blocks the fusion of HIV-1 envelope with the membrane of CD4-positive cells. The binding of this antibody to its epitope was demonstrated to strongly depend on the presence of $\mathrm{Ca}^{2+}$ ions ${ }^{82}$. Real-time biosensor experiments demonstrated that while the binding of Q425 to CD4 was negligible in the absence of $\mathrm{Ca}^{2+}$ ions $\left(\mathrm{K}_{\mathrm{D}}\right.$ of $\left.83 \mu \mathrm{M}\right)$, it increased by 55,000-fold in the presence of $\mathrm{Ca}^{2+}$. Q425 demonstrated a high selectivity for $\mathrm{Ca}^{2+}$, since other bivalent metal ions had only minimal or no effect on its binding to CD4. Structural analyses of Q425 indicate that the structure of its antigen-binding site (or its overall structure) is not affected by the absence or presence of $\mathrm{Ca}^{2+}$. The $\mathrm{Ca}^{2+}$ ion occupies a central position in the antigen-binding site and interacts with the side chains of amino acids Asn32a, Asp32 and Glu50 from the CDR H3, CDR L1, and CDR L2, respectively, as well as with a backbone carbonyl of Ser91 from the CDR L3. The $\mathrm{Ca}^{2+}$ ion is displayed at the surface of Q425 in such a manner that it allows the establishment of metal coordination bonds with 
amino acids of the target antigen ${ }^{82}$. Thus, $\mathrm{Ca}^{2+}$ in $\mathrm{Q} 425$ is used as an interfacial cofactor that bridges the antibody to the antigen.

Another case of metal-dependent antigen recognition is described for the humanized sphingosine-1 phosphate-specific IgG LT1009 ${ }^{83}$. LT1009 was developed as a potential therapeutic antibody for neoplastic diseases and macular degeneration. Structural analyses of the complex of LT1009 with its antigen revealed that the antibody uses two $\mathrm{Ca}^{2+}$ ions as a bridge between its paratope and sphingosine-1-phosphate ${ }^{83}$. Both $\mathrm{Ca}^{2+}$ ions are bound in close proximity to each other by side chains of aspartic acids from the CDR L1 and CDR L3 loops. The $\mathrm{Ca}^{2+}$ ions directly interact with the phosphate group from sphingosine-1-phosphate. The interaction between LT1009 and its antigen was completely abrogated in the presence of chelating agents, or after replacement of either $\mathrm{Ca}^{2+}$-binding aspartic acid with an alanine ${ }^{83}$. These experiments highlight the critical role played by $\mathrm{Ca}^{2+}$ ions as cofactors in the determination of the antigen specificity of some antibodies. It is noteworthy that both Q425 and LT1009 exhibit high levels of homology, with differences in the positions of the $\mathrm{Ca}^{2+}$ binding residues.

The anti-human protein $\mathrm{C}$ antibody HPC4 is another antibody that gains specificity for its target antigen only in the presence of $\mathrm{Ca}^{2+}$ ions. In this case, the $\mathrm{Ca}^{2+}$ ions were proposed to bind to the antigen-binding site of the antibody ${ }^{84}$, but it was not demonstrated whether, similarly to Q425 and LT1009, HPC4 uses the metal ions as interfacial cofactor for interacting with its cognate antigen. Other investigations demonstrated that exposure of pooled human IgG obtained from plasma of more than 3000 healthy donors (intravenous immunoglobulins, IVIg) to $\mathrm{Fe}^{2+}$ ions results in a considerable broadening of the repertoire of recognized antigens. Interestingly, the diversification of antigenic specificities was not observed in the presence of other transition metal ions ${ }^{85}$. Whether $\mathrm{Fe}^{2+}$ ions directly contribute 
to antigen binding (as is the case with $\mathrm{Ca}^{2+}$ ions) or instead induce structural changes in the $\mathrm{V}$ regions of some $\operatorname{IgG}$ was however not deciphered.

\section{[H3] Use of haem.}

Early studies on the distribution of essential enzyme cofactors in healthy human plasma indicated that the $\gamma$-globulin fraction binds significant amounts of riboflavin, thiamine and nicotinic acid, which are essential cofactors for numerous enzymes ${ }^{86}$. Further studies demonstrated that human pooled Igs bind the riboflavin-containing cofactors flavin mononucleotide (FMN) and flavin adenine dinucleotide (FAD) with higher affinity than albumin, which is a known transporter of aromatic compounds in plasma ${ }^{87-89}$. Antibodies isolated from patients with myeloma have also been shown to bind riboflavin with high affinity $^{90}$, and the crystal structure of one such antibody-riboflavin complex has been solved ${ }^{91}$. Circulating Igs have been also reported to interact with $\mathrm{ATP}^{92}$ and high frequencies of human antibodies inherently binding to xenobiotic aromatic substances (nitrophenols) have been reported since the pioneering immunochemistry works on $\operatorname{Igs}^{49,93,94}$.

Haem (iron protoporphyrin IX) has also been shown to interact with circulating antibodies $^{95}$ and there is compelling evidence that it can diversify their antigen-binding specificities. Haem is an essential heterocyclic compound that acts as a prosthetic group in many proteins. Under homeostasic conditions, haem is bound to haemoproteins (hemoglobin, myoglobin, cytochromes and many others) and is sequestered intracellularly. However, haem can be released extracellularly during various pathological conditions associated with haemolysis, such as malaria, sickle cell disease, rhabdomyolysis, ischemia-reperfusion injury, autoimmune diseases and sepsis ${ }^{96,97}$. Free haem is a very reactive molecule and has profound effects on different plasma proteins, including $\operatorname{Igs}^{98}$. 
Studies by McIntyre and colleagues showed that incubation of whole human blood or plasma with haem-containing medium results in the appearance of a considerable antibody reactivity against different phospholipids ${ }^{99}$. Likewise, exposure of purified pooled human IgG to haem leads to the acquisition of a considerable reactivity to many prototypical autoantigens used as targets for the diagnosis of autoimmune diseases ${ }^{100-102}$. Further investigations revealed that the interaction of human antibodies with haem induces a diversification in reactivity not only toward autoantigens but also toward pathogen-derived antigens ${ }^{95,103,104}$. It is noteworthy that binding affinities for the antigens recognized by haem-exposed IgG are substantial ${ }^{105}$. Binding analyses of repertoires of human monoclonal antibodies revealed that, depending on the studied antigen, the fraction of $\operatorname{IgG}$ that acquire novel antigen-binding specificities after contact with haem ranges between 9 and $24 \%{ }^{103,104}$. Of note, the repertoire analyses demonstrated that haem-sensitive IgG had significantly lower number of somatic mutations in the genes encoding their $\mathrm{V}$ regions as compared to IgG that did not change their specificity upon exposure to haem ${ }^{103,104}$.

Further studies demonstrated that the haem-induced acquisition of novel antigenbinding specificities is due to a direct binding of haem to antibodies. The most probable interaction site of haem is in the $\mathrm{V}$ region, in proximity or overlapping with the antigencombining site ${ }^{105,106}$. Once bound to the antigen-binding site, haem might be used as an interfacial cofactor for engagement with the antigen ${ }^{95,106}$ (FIG. 4B). The diversification of antigen-binding specificities of normal $\operatorname{IgG}$ by haem could be explained by the peculiar features of the latter. Indeed, the unique physicochemical characteristics of haem, the presence of aromatic, hydrophobic, metal coordinating and anionic groups, offer an enormous diversity of possible variants of non-covalent contacts ${ }^{107}$ prone to enrich the physicochemical heterogeneity of the antigen-combining sites and the overall tendency of antibodies to interact with proteins they are not initially specific for. 
The biological significance of the broadening of the antigen-binding diversity of antibody repertoires by haem remains unclear. Efforts have focused on determining the therapeutic effect of antibodies pre-treated in vitro with haem and then administered in models of inflammatory and autoimmune diseases. For example, in contrast to mice injected with native pooled $\mathrm{IgG}$, mice treated with a single dose of $\mathrm{IgG}$ exposed to haem were better protected from LPS-induced systemic inflammation ${ }^{108}$. A beneficial role of haem-bound IgG has also been demonstrated in a model of autoimmune diabetes ${ }^{109}$. In the latter work, the protective effect of haem-exposed IgG was associated with a decrease in the circulating levels of pro-inflammatory cytokines and in the infiltration of cytotoxic $\mathrm{T}$ cells in the pancreatic islets. Taken together, these results suggest that haem-induced diversification of antigenbinding specificity of IgG may have systemic and non-specific immunomodulatory effect in situations associated with liberation of extracellular haem.

In conclusion, certain antibodies can bind to low molecular weight compounds $\left(\mathrm{Ca}^{2+}\right.$ ions or haem) and use these compounds as interfacial cofactors for recognition of diverse antigens. The cofactors enrich the reactivity of the binding interface, thus allowing recognition of larger set of target antigens.

\section{[H1] Relevance of unconventional diversification}

In the preceding sections we have presented evidence for the existence of unconventional strategies that broaden the antibody repertoire. These mechanisms are either based on the intrinsic structural heterogeneity of the paratope or involve covalent or non-covalent chemical modifications of the antigen-binding region. The use of these unconventional diversification strategies is not independent from that of conventional diversification mechanisms. Instead, in most of the cases, classical mechanisms pre-determine the engagement of alternative strategies. Thus, somatic mutations introduced in $\mathrm{V}$ region genes can result in unique 
sequence motifs, which are specific targets for enzymes adding glycans or sulphate groups to asparagine or tyrosine residues, respectively. In addition, the increased structural diversity of antigen-binding sites might be pre-determined by the elevated number of particular amino acids at specific locations in the $\mathrm{V}$ regions or by the presence of long CDRs. For example, polypeptide sequences rich in glycine residues possess high intrinsic conformational dynamics $^{110,111}$. Similarly, the dramatic reconfiguration of the binding site of the HIV-1 neutralizing antibody $2 \mathrm{G} 12$ results from somatic mutations that weaken contacts in the $\mathrm{V}_{\mathrm{H}}: \mathrm{V}_{\mathrm{L}}$ interface and others that strengthen contacts in the $\mathrm{V}_{\mathrm{H}}: \mathrm{V}_{\mathrm{H}}$ interfaces ${ }^{78}$. Taken together, these results strongly suggest that, with the possible exception of the incorporation of large nonimmunoglobulin protein sequences in $\mathrm{Ig} \mathrm{V}$ regions ${ }^{9,}{ }^{12}$, the same evolutionary principles of mutation and selection responsible for the diversification of antibody repertoires govern the diversification of antigen-binding specificities by unconventional strategies.

A prominent feature of these unconventional pathways for expanding the antigenbinding diversity of antibodies is that they are frequently implicated in the recognition of pathogens with high antigenic variability, such as HIV-1, influenza virus and Plasmodium sp. This fact implies that the immune system recruits alternative strategies of generating diversity in order to compensate for the rapid pace of changes of certain target pathogens. We propose that the structural restrictions of the canonical topology of the $\mathrm{V}$ region impose limits on the ability of antibodies to encompass the breadth of possible target epitopes. Incorporation of uncommon chemical groups (such as carbohydrates, sulphates, haem, or metal ions), use of proteins or reconfiguration of the topology of the antigen-combining sites by a conformational isomerism might all compensate for the structural hurdles imposed by different antigens.

The existence of different unorthodox mechanisms for the generation of antigenbinding diversity clearly demonstrates that the adaptive immune response is characterized by extraordinary adaptability. Thus, boundaries defining the limits of repertoire diversity can 
fluctuate and be crossed when the system cannot efficiently cope with the pathogens (FIG. 5). Most probably, the continuous persistence of highly variable pathogens is the essential trigger for launching some of the non-standard diversification pathways. The unconventional pathways for diversification of antibody specificities are used only as a last resort, possibly as a result of their expense in terms of energy resources and risk of unwanted reactivities, in particular by overcoming immune-tolerance checkpoints. For example, large rearrangements of the genome of $\mathrm{B}$ cells in patients with malaria that result in the incorporation of non- $\mathrm{Ig}$ proteins in the $\mathrm{V}$ regions of Abs may represent a substantial risk for the malignant transformation of B cells. In this respect, an elevated prevalence of B cell lymphoma has been reported in malaria patients ${ }^{13}$. Likewise, antibodies with binding sites existing in different structural conformers may have potentially pathogenic levels of binding polyreactivity and autoreactivity; such antibodies will presumably be characterized by a short circulatory half$\operatorname{life}^{112}$.

The unconventional post-translational diversification of antigen-binding specificities might also be triggered in cases of dramatic changes in the microenvironment. Thus, severe tissue damage or haemolysis may result in the release of haem into the extracellular space, which would bind to some of the circulating antibodies and induce the appearance of new antigen-specificities. One can speculate that the recruitment of novel antigen-binding specificities in such situations contributes to antibody-mediated clearance of dead cells or neutralization of endogenous pro-inflammatory mediators, such as HMGB2, histones and cytokines.

With the advent of high-throughput technologies for the sequencing and analysis of vast human Ig repertoires, one may anticipate the discovery of additional mechanisms for diversification of immune specificities. Thus, additional types of post-translational modifications might be described to contribute to the chemical variability of the antigen- 
combining sites. Moreover, cofactors other than $\mathrm{Ca}^{2+}$ ions and haem may also be recruited by antibodies for modulating their specificities. Notably, although at very low frequency some human Igs possess cysteine residues in their CDR3 loops ${ }^{113}{ }^{114}$; the presence of this residue would provide surface exposed sulfhydryl group that could serve as a tag for binding via formation of disulfide bonds with other sulfhydryl group-containing compounds (glutathione, homocysteine, coenzyme A) or even entire proteins to $\mathrm{V}$ regions of antibodies. These modifications would have a dramatic impact on the binding specificity. In addition to highthroughput sequencing, mass spectrometry analyses of large antibody repertoires would contribute to the identification, at the protein levels, of new types of modifications of antibodies and, concomitantly, of novel pathways for diversification of antigen-binding specificity.

All strategies for unorthodox diversification of antibody specificities described in the present review have been illustrated in the case of human or mouse antibodies. It is unknown at what stage in phylogeny these mechanisms first appeared. One can speculate that the emergence of somatic mutagenesis is the pivotal moment for all mechanisms but conformational heterogeneity. It is noteworthy that antibodies with untypical configurations of $\mathrm{V}$ regions such as single $\mathrm{V}$ domain antibodies (present in sharks and camelides) ${ }^{115}$ or abnormally enlarged CDR H3 (present in cattle) ${ }^{116}$ have been reported. Consequently, studies of antibody repertoires in different species can reveal yet other unorthodox tactics for generation of antibody diversity.

Antibodies might also use different unconventional strategies simultaneously for diversification of their binding specificities. For example, there is a high probability for indelcontaining antibodies to be glycosylated or sulphated as well. Antibodies with high degree of structural heterogeneity may simultaneously have post-translational modifications in $\mathrm{V}$ 
domain. Indeed, structural analyses of HIV-1-neutralizing antibodies that carry sulphated tyrosines revealed that their CDR H3 loops are characterized by a high level of conformational flexibility ${ }^{24}$. We may expect synergy between different diversification mechanisms (conventional and/or non-conventional) to generate an even higher degree of variable antigen-binding sites.

\section{[H1] Conclusion}

Here, we have described and classified different unconventional mechanisms for the diversification of antigen-binding specificities of antibodies. These processes testify for the spectacular adaptability of humoral immune responses. We propose that antibody antigenbinding diversity acquired by unorthodox mechanisms represents a third layer of diversification of immune repertoires beyond the variability introduced by (mere) recombination and mutagenesis (FIG. 5). 


\section{References}

1. Flajnik, M.F. A cold-blooded view of adaptive immunity. Nat. Rev. Immunol. 18, 438453 (2018).

2. Lu, L.L., Suscovich, T.J., Fortune, S.M. \& Alter, G. Beyond binding: antibody effector functions in infectious diseases. Nat. Rev. Immunol. 18, 46-61 (2018).

3. Saada, R., Weinberger, M., Shahaf, G. \& Mehr, R. Models for antigen receptor gene rearrangement: CDR3 length. Immunol. Cell Biol. 85, 323-32 (2007).

4. Collins, A.M. \& Jackson, K.J.L. On being the right size: antibody repertoire formation in the mouse and human. Immunogenetics 70, 143-158 (2018).

5. Wardemann, H. \& Busse, C.E. Novel Approaches to Analyze Immunoglobulin Repertoires. Trends Immunol. 38, 471-482 (2017).

6. Imkeller, K. \& Wardemann, H. Assessing human B cell repertoire diversity and convergence. Immunol. Rev. 284, 51-66 (2018).

7. Klein, F. et al. Antibodies in HIV-1 vaccine development and therapy. Science 341, 1199-1204 (2013).

8. Corti, D. \& Lanzavecchia, A. Broadly neutralizing antiviral antibodies. Annu. Rev. Immunol. 31, 705-742 (2013).

9. Tan, J. et al. A LAIR1 insertion generates broadly reactive antibodies against malaria variant antigens. Nature 529, 105-109 (2016).

This article demonstrates that some antibodies isolated from malaria patients have insertion of LAIR1 protein in their $V_{H}$ regions.

10. Meyaard, L. et al. LAIR-1, a novel inhibitory receptor expressed on human mononuclear leukocytes. Immunity 7, 283-290 (1997).

11. Hsieh, F.L. \& Higgins, M.K. The structure of a LAIR1-containing human antibody reveals a novel mechanism of antigen recognition. Elife 6 (2017).

This paper reveals the crystal structure of an antibody that incorporates LAIR1 in its $\mathrm{V}$ region.

12. Pieper, K. et al. Public antibodies to malaria antigens generated by two LAIR1 insertion modalities. Nature 548, 597-601 (2017).

13. Robbiani, D.F. et al. Plasmodium Infection Promotes Genomic Instability and AIDDependent B Cell Lymphoma. Cell 162, 727-737 (2015).

14. Briney, B.S., Willis, J.R. \& Crowe, J.E., Jr. Location and length distribution of somatic hypermutation-associated DNA insertions and deletions reveals regions of antibody structural plasticity. Genes Immun. 13, 523-9 (2012).

15. Wilson, P.C. et al. Somatic hypermutation introduces insertions and deletions into immunoglobulin V genes. J. Exp. Med. 187, 59-70 (1998).

16. Bowers, P.M. et al. Nucleotide insertions and deletions complement point mutations to massively expand the diversity created by somatic hypermutation of antibodies. $J$. Biol. Chem. 289, 33557-33567 (2014).

17. Kepler, T.B. et al. Immunoglobulin gene insertions and deletions in the affinity maturation of HIV-1 broadly reactive neutralizing antibodies. Cell Host Microbe 16, 304-313 (2014).

This article shows that the frequency of indels in $\mathrm{V}$ regions is increased in antibodies from HIV-1 infected individuals and in broadly neutralizing HIV-1 antibodies.

18. Krause, J.C. et al. An insertion mutation that distorts antibody binding site architecture enhances function of a human antibody. MBio 2, e00345-10 (2011).

19. Klein, F. et al. Somatic mutations of the immunoglobulin framework are generally required for broad and potent HIV-1 neutralization. Cell 153, 126-138 (2013). 
This work reveals the molecular mechanism of indel-mediated optimization of the neutralizing potential of a broadly neutralizing HIV-1 antibody.

20. Jennewein, M.F. \& Alter, G. The Immunoregulatory Roles of Antibody Glycosylation. Trends Immunol 38, 358-372 (2017).

21. Moore, K.L. The biology and enzymology of protein tyrosine O-sulfation. J. Biol. Chem. 278, 24243-24246 (2003).

22. Ouyang, Y., Lane, W.S. \& Moore, K.L. Tyrosylprotein sulfotransferase: purification and molecular cloning of an enzyme that catalyzes tyrosine O-sulfation, a common posttranslational modification of eukaryotic proteins. Proc. Natl. Acad. Sci. U.S.A. 95, 2896-28901 (1998).

23. Choe, $\mathrm{H}$. et al. Tyrosine sulfation of human antibodies contributes to recognition of the CCR5 binding region of HIV-1 gp120. Cell 114, 161-170 (2003).

24. Huang, C.C. et al. Structural basis of tyrosine sulfation and VH-gene usage in antibodies that recognize the HIV type 1 coreceptor-binding site on gp120. Proc. Natl. Acad. Sci. U.S.A. 101, 2706-2711 (2004).

25. Farzan, M. et al. Tyrosine sulfation of the amino terminus of CCR5 facilitates HIV-1 entry. Cell 96, 667-676 (1999).

26. Huang, C.C. et al. Structures of the CCR5 N terminus and of a tyrosine-sulfated antibody with HIV-1 gp120 and CD4. Science 317, 1930-1934 (2007).

This article shows molecular details about the role of tyrosine sulphation in the interaction of an antibody with its target antigen.

27. Pejchal, R. et al. Structure and function of broadly reactive antibody PG16 reveal an H3 subdomain that mediates potent neutralization of HIV-1. Proc. Natl. Acad. Sci. U.S.A. 107, 11483-11488 (2010).

This work presents evidence for the functional impact of sulphation of tyrosine in antibody-mediated neutralization of HIV-1.

28. Changela, A. et al. Crystal structure of human antibody 2909 reveals conserved features of quaternary structure-specific antibodies that potently neutralize HIV-1. $J$. Virol. 85, 2524-2535 (2011).

29. van de Bovenkamp, F.S., Hafkenscheid, L., Rispens, T. \& Rombouts, Y. The Emerging Importance of IgG Fab Glycosylation in Immunity. J. Immunol. 196, 14351441 (2016).

30. Hamza, N. et al. Ig gene analysis reveals altered selective pressures on Ig-producing cells in parotid glands of primary Sjogren's syndrome patients. J. Immunol. 194, 514521 (2015).

31. Rombouts, Y. et al. Extensive glycosylation of ACPA-IgG variable domains modulates binding to citrullinated antigens in rheumatoid arthritis. Ann. Rheum. Dis. 75, 578-585 (2016).

32. Hafkenscheid, L. et al. Structural Analysis of Variable Domain Glycosylation of AntiCitrullinated Protein Antibodies in Rheumatoid Arthritis Reveals the Presence of Highly Sialylated Glycans. Mol. Cell. Proteomics 16, 278-287 (2017).

33. van de Bovenkamp, F.S. et al. Variable Domain N-Linked Glycans Acquired During Antigen-Specific Immune Responses Can Contribute to Immunoglobulin G Antibody Stability. Front. Immunol. 9, 740 (2018).

34. van de Bovenkamp, F.S. et al. Adaptive antibody diversification through N-linked glycosylation of the immunoglobulin variable region. Proc. Natl. Acad. Sci. U.S.A. 115, 1901-1906 (2018).

This study demonstrates the importance of glycosylation of $\mathrm{V}$ regions for the diversification of human antibody repertoires. 
35. Wallick, S.C., Kabat, E.A. \& Morrison, S.L. Glycosylation of a VH residue of a monoclonal antibody against alpha (1----6) dextran increases its affinity for antigen. $J$. Exp. Med. 168, 1099-1109 (1988).

36. Leibiger, H., Wustner, D., Stigler, R.D. \& Marx, U. Variable domain-linked oligosaccharides of a human monoclonal IgG: structure and influence on antigen binding. Biochem. J. 338 ( Pt 2), 529-538 (1999).

37. Khurana, S., Raghunathan, V.\& Salunke, D.M. The variable domain glycosylation in a monoclonal antibody specific to GnRH modulates antigen binding. Biochem. Biophys. Res. Commun. 234, 465-469 (1997).

38. Jacquemin, M. et al. Variable region heavy chain glycosylation determines the anticoagulant activity of a factor VIII antibody. J. Thromb. Haemost. 4, 1047-1055 (2006).

39. Song, R., Oren, D.A., Franco, D., Seaman, M.S. \& Ho, D.D. Strategic addition of an N-linked glycan to a monoclonal antibody improves its HIV-1-neutralizing activity. Nat. Biotechnol. 31, 1047-1052 (2013).

40. Sabouri, Z. et al. Redemption of autoantibodies on anergic B cells by variable-region glycosylation and mutation away from self-reactivity. Proc. Natl. Acad. Sci. U.S.A. 111, E2567-2575 (2014).

41. Chuang, G.Y. et al. Eliminating antibody polyreactivity through addition of N-linked glycosylation. Protein Sci. 24, 1019-1030 (2015).

42. Boehr, D.D., Nussinov, R. \& Wright, P.E. The role of dynamic conformational ensembles in biomolecular recognition. Nat. Chem. Biol. 5, 789-796 (2009).

43. Tokuriki, N. \& Tawfik, D.S. Protein dynamism and evolvability. Science 324, 203207 (2009).

44. James, L.C. \& Tawfik, D.S. Conformational diversity and protein evolution--a 60year-old hypothesis revisited. Trends Biochem. Sci. 28, 361-368 (2003).

45. Yin, J., Beuscher, A.E.t., Andryski, S.E., Stevens, R.C. \& Schultz, P.G. Structural plasticity and the evolution of antibody affinity and specificity. J. Mol. Biol. 330, 651656 (2003).

46. Manivel, V., Sahoo, N.C., Salunke, D.M. \& Rao, K.V. Maturation of an antibody response is governed by modulations in flexibility of the antigen-combining site. Immunity 13, 611-620 (2000).

47. Manivel, V., Bayiroglu, F., Siddiqui, Z., Salunke, D.M. \& Rao, K.V. The primary antibody repertoire represents a linked network of degenerate antigen specificities. $J$. Immunol. 169, 888-897 (2002).

48. Notkins, A.L. Polyreactivity of antibody molecules. Trends Immunol. 25, 174-179 (2004).

49. Eisen, H.N. \& Chakraborty, A.K. Evolving concepts of specificity in immune reactions. Proc. Natl. Acad. Sci. U.S.A. 107, 22373-22380 (2010).

50. Wedemayer, G.J., Patten, P.A., Wang, L.H., Schultz, P.G. \& Stevens, R.C. Structural insights into the evolution of an antibody combining site. Science 276, 1665-1669 (1997).

51. Jimenez, R., Salazar, G., Baldridge, K.K. \& Romesberg, F.E. Flexibility and molecular recognition in the immune system. Proc. Natl. Acad. Sci. U.S.A. 100, 92-97 (2003).

52. Jimenez, R., Salazar, G., Yin, J., Joo, T. \& Romesberg, F.E. Protein dynamics and the immunological evolution of molecular recognition. Proc. Natl. Acad. Sci. U.S.A. 101, 3803-3808 (2004).

53. Nguyen, H.P. et al. Germline antibody recognition of distinct carbohydrate epitopes. Nat. Struct. Biol. 10, 1019-1025 (2003). 
54. Zimmermann, J. et al. Antibody evolution constrains conformational heterogeneity by tailoring protein dynamics. Proc. Natl. Acad. Sci. U.S.A. 103, 13722-13727 (2006).

55. Thorpe, I.F. \& Brooks, C.L., 3rd. Molecular evolution of affinity and flexibility in the immune system. Proc. Natl. Acad. Sci. U.S.A. 104, 8821-8826 (2007).

56. Schmidt, A.G. et al. Preconfiguration of the antigen-binding site during affinity maturation of a broadly neutralizing influenza virus antibody. Proc. Natl. Acad. Sci. U.S.A. 110, 264-269 (2013).

57. Jeliazkov, J.R. et al. Repertoire Analysis of Antibody CDR-H3 Loops Suggests Affinity Maturation Does Not Typically Result in Rigidification. Front. Immunol. 9, 413 (2018).

58. Ovchinnikov, V., Louveau, J.E., Barton, J.P., Karplus, M. \& Chakraborty, A.K. Role of framework mutations and antibody flexibility in the evolution of broadly neutralizing antibodies. Elife 7 (2018).

59. Acierno, J.P., Braden, B.C., Klinke, S., Goldbaum, F.A. \& Cauerhff, A. Affinity maturation increases the stability and plasticity of the $\mathrm{Fv}$ domain of anti-protein antibodies. J. Mol. Biol. 374, 130-146 (2007).

60. Haynes, B.F. et al. Cardiolipin polyspecific autoreactivity in two broadly neutralizing HIV-1 antibodies. Science 308, 1906-1908 (2005).

61. Liu, M. et al. Polyreactivity and autoreactivity among HIV-1 antibodies. J. Virol. 89, 784-798 (2015).

62. Mouquet, H. et al. Polyreactivity increases the apparent affinity of anti-HIV antibodies by heteroligation. Nature 467, 591-595 (2010).

63. Prigent, J. et al. Conformational Plasticity in Broadly Neutralizing HIV-1 Antibodies Triggers Polyreactivity. Cell Rep. 23, 2568-2581 (2018).

64. Erijman, A., Aizner, Y. \& Shifman, J.M. Multispecific recognition: mechanism, evolution, and design. Biochemistry 50, 602-611 (2011).

65. Vogt, A.D. \& Di Cera, E. Conformational selection or induced fit? A critical appraisal of the kinetic mechanism. Biochemistry 51, 5894-5902 (2012).

66. Foote, J. \& Milstein, C. Conformational isomerism and the diversity of antibodies. Proc. Natl. Acad. Sci. U.S.A. 91, 10370-10374 (1994).

67. James, L.C. \& Tawfik, D.S. Structure and kinetics of a transient antibody binding intermediate reveal a kinetic discrimination mechanism in antigen recognition. Proc. Natl. Acad. Sci. U.S.A. 102, 12730-12735 (2005).

68. James, L.C., Roversi, P. \& Tawfik, D.S. Antibody multispecificity mediated by conformational diversity. Science 299, 1362-1367 (2003).

This study provides structural evidence for the existence of conformational isomerism in some antibodies.

69. Wardemann, H. et al. Predominant autoantibody production by early human B cell precursors. Science 301, 1374-1377 (2003).

70. Tiller, T. et al. Autoreactivity in human IgG+ memory B cells. Immunity 26, 205-213 (2007).

71. Benckert, J. et al. The majority of intestinal $\operatorname{IgA}+$ and $\mathrm{IgG}+$ plasmablasts in the human gut are antigen-specific. J. Clin. Invest. 121, 1946-1955 (2011).

72. Bunker, J.J. et al. Natural polyreactive IgA antibodies coat the intestinal microbiota. Science 358, eean6619 (2017).

73. Jones, D.D., DeIulio, G.A. \& Winslow, G.M. Antigen-driven induction of polyreactive IgM during intracellular bacterial infection. J. Immunol. 189, 1440-1447 (2012).

74. Mouquet, H. \& Nussenzweig, M.C. Polyreactive antibodies in adaptive immune responses to viruses. Cell. Mol. Life Sci. 69, 1435-1445 (2012). 
75. Warter, L., Appanna, R. \& Fink, K. Human poly- and cross-reactive anti-viral antibodies and their impact on protection and pathology. Immunol. Res. 53, 148-161 (2012).

76. Trama, A.M. et al. HIV-1 envelope gp41 antibodies can originate from terminal ileum B cells that share cross-reactivity with commensal bacteria. Cell Host Microbe 16, 215-226 (2014).

77. Vogt, A.D. \& Di Cera, E. Conformational selection is a dominant mechanism of ligand binding. Biochemistry 52, 5723-5729 (2013).

78. Calarese, D.A. et al. Antibody domain exchange is an immunological solution to carbohydrate cluster recognition. Science 300, 2065-2071 (2003).

This paper reveals that a broadly neutralizing HIV-1 antibody uses V domain swapping for achievement of high affinity binding to a carbohydrate epitope on the surface of gp120.

79. Calarese, D.A. et al. Dissection of the carbohydrate specificity of the broadly neutralizing anti-HIV-1 antibody 2G12. Proc. Natl. Acad. Sci. U.S.A. 102, 1337213377 (2005).

80. Barnes, C.O. et al. Structural characterization of a highly-potent V3-glycan broadly neutralizing antibody bound to natively-glycosylated HIV-1 envelope. Nat. Commun. 9, 1251 (2018).

81. Imkeller, K. et al. Antihomotypic affinity maturation improves human B cell responses against a repetitive epitope. Science 360, 1358-1362 (2018).

This study demonstrates that homotypic interaction between $\mathbf{V}$ regions of two different antibody molecules facilitates recognition of repetitive antigens.

82. Zhou, T., Hamer, D.H., Hendrickson, W.A., Sattentau, Q.J. \& Kwong, P.D. Interfacial metal and antibody recognition. Proc. Natl. Acad. Sci. U.S.A. 102, 14575-14580 (2005).

83. Wojciak, J.M. et al. The crystal structure of sphingosine-1-phosphate in complex with a Fab fragment reveals metal bridging of an antibody and its antigen. Proc. Natl. Acad. Sci. U.S.A. 106, 17717-17722 (2009).

References 82 and 83 show that certain antibodies use $\mathrm{Ca}^{2+}$ ions as an interfacial cofactor for antigen recognition.

84. Stearns, D.J., Kurosawa, S., Sims, P.J., Esmon, N.L. \& Esmon, C.T. The interaction of a $\mathrm{Ca} 2+$-dependent monoclonal antibody with the protein $\mathrm{C}$ activation peptide region. Evidence for obligatory $\mathrm{Ca} 2+$ binding to both antigen and antibody. J. Biol. Chem. 263, 826-832 (1988).

85. Dimitrov, J.D. et al. Ferrous ions and reactive oxygen species increase antigen-binding and anti-inflammatory activities of immunoglobulin G. J. Biol. Chem. 281, 439-446 (2006).

86. Baker, H., Frank, O., Feingold, S. \& Leevy, C.M. Vitamin distribution in human plasma proteins. Nature 215, 84-85 (1967).

87. Innis, W.S., McCormick, D.B. \& Merrill, A.H., Jr. Variations in riboflavin binding by human plasma: identification of immunoglobulins as the major proteins responsible. Biochem. Med. 34, 151-165 (1985).

88. Watson, C.D. \& Ford, H.C. High-affinity binding of riboflavin and FAD by immunoglobulins from normal human serum. Biochem. Int. 16, 1067-1074 (1988).

89. Nieva, J., Kerwin, L., Wentworth, A.D., Lerner, R.A. \& Wentworth, P., Jr. Immunoglobulins can utilize riboflavin (Vitamin B2) to activate the antibodycatalyzed water oxidation pathway. Immunol. Lett. 103, 33-38 (2006).

90. Stoppini, M. et al. Characterization of the two unique human anti-flavin monoclonal immunoglobulins. Eur. J. Biochem. 228, 886-893 (1995). 
91. Zhu, X., Wentworth, P., Jr., Kyle, R.A., Lerner, R.A. \& Wilson, I.A. Cofactorcontaining antibodies: crystal structure of the original yellow antibody. Proc. Natl. Acad. Sci. U.S.A. 103, 3581-3585 (2006).

92. Rajagopalan, K. et al. Novel unconventional binding site in the variable region of immunoglobulins. Proc. Natl. Acad. Sci. U.S.A. 93, 6019-6024 (1996).

93. Karjalainen, K. \& Makela, O. Concentrations of three hapten-binding immunoglobulins in pooled normal human serum. Eur. J. Immunol. 6, 88-93 (1976).

94. McEnaney, P.J., Parker, C.G., Zhang, A.X. \& Spiegel, D.A. Antibody-recruiting molecules: an emerging paradigm for engaging immune function in treating human disease. Chem. Biol. 7, 1139-1151 (2012).

95. Dimitrov, J.D. et al. Antibodies use heme as a cofactor to extend their pathogen elimination activity and to acquire new effector functions. J. Biol. Chem. 282, 2669626706 (2007).

This study shows that some antibodies use haem as a cofactor for the diversification of antigen binding specificity.

96. Wagener, F.A. et al. Different faces of the heme-heme oxygenase system in inflammation. Pharmacol. Rev. 55, 551-571 (2003).

97. Soares, M.P. \& Bozza, M.T. Red alert: labile heme is an alarmin. Curr. Opin. Immunol. 38, 94-100 (2016).

98. Roumenina, L.T., Rayes, J., Lacroix-Desmazes, S. \& Dimitrov, J.D. Heme: Modulator of Plasma Systems in Hemolytic Diseases. Trends Mol. Med. 22, 200-213 (2016).

99. McIntyre, J.A. The appearance and disappearance of antiphospholipid autoantibodies subsequent to oxidation--reduction reactions. Thromb. Res. 114, 579-87 (2004).

100. McIntyre, J.A., Wagenknecht, D.R. \& Faulk, W.P. Autoantibodies unmasked by redox reactions. J. Autoimmun. 24, 311-317 (2005).

101. McIntyre, J.A., Wagenknecht, D.R. \& Faulk, W.P. Redox-reactive autoantibodies: detection and physiological relevance. Autoimmun. Rev. 5, 76-83 (2006).

102. McIntyre, J.A. \& Faulk, W.P. Redox-reactive autoantibodies: biochemistry, characterization, and specificities. Clin. Rev. Allergy Immunol. 37, 49-54 (2009).

103. Lecerf, M. et al. Prevalence and Gene Characteristics of Antibodies with Cofactorinduced HIV-1 Specificity. J. Biol. Chem. 290, 5203-5213 (2015).

104. Gupta, N. et al. Neutralization of Japanese Encephalitis Virus by heme-induced broadly reactive human monoclonal antibody. Sci. Rep. 5, 16248 (2015).

105. Hadzhieva, M. et al. Mechanism and Functional Implications of the Heme-Induced Binding Promiscuity of IgE. Biochemistry 54, 2061-2072 (2015).

106. Dimitrov, J.D. et al. A cryptic polyreactive antibody recognizes distinct clades of HIV-1 glycoprotein 120 by an identical binding mechanism. J. Biol. Chem. 289, 17767-79 (2014).

107. Kuhl, T. \& Imhof, D. Regulatory Fe(II/III) heme: the reconstruction of a molecule's biography. Chembiochem 15, 2024-2035 (2014).

108. Djoumerska-Alexieva, I., Roumenina, L.T., Stefanova, T., Vassilev, T. \& Dimitrov, J.D. Heme-Exposed Pooled Therapeutic IgG Improves Endotoxemia Survival. Inflammation 40, 117-122 (2017).

109. Pavlovic, S. et al. Intravenous immunoglobulins exposed to heme (heme IVIG) are more efficient than IVIG in attenuating autoimmune diabetes. Clin. Immunol. 138, 162-171 (2010).

110. Vihinen, M., Torkkila, E. \& Riikonen, P. Accuracy of protein flexibility predictions. Proteins 19, 141-9 (1994).

111. Radivojac, P. et al. Protein flexibility and intrinsic disorder. Protein Sci. 13, 71-80 (2004). 
112. Sigounas, G., Harindranath, N., Donadel, G. \& Notkins, A.L. Half-life of polyreactive antibodies. J. Clin. Immunol. 14, 134-140 (1994).

113. Robin, G. et al. Restricted diversity of antigen binding residues of antibodies revealed by computational alanine scanning of 227 antibody-antigen complexes. J. Mol. Biol. 426, 3729-3743 (2014).

114. Hong, B. et al. In-Depth Analysis of Human Neonatal and Adult IgM Antibody Repertoires. Front. Immunol. 9, 128 (2018).

115. Brooks, C.L., Rossotti, M.A. \& Henry, K.A. Immunological Functions and Evolutionary Emergence of Heavy-Chain Antibodies. Trends Immunol. 39, 956-960 (2018).

116. Wang, F. et al. Reshaping antibody diversity. Cell 153, 1379-93 (2013).

117. Scheid, J.F. et al. Sequence and structural convergence of broad and potent HIV antibodies that mimic CD4 binding. Science 333, 1633-7 (2011).

118. Pettersen, E.F. et al. UCSF Chimera--a visualization system for exploratory research and analysis. J. Comput. Chem. 25, 1605-1612 (2004).

119. Dimitrov, J.D. \& Vassilev, T.L. Cofactor-mediated protein promiscuity. Nat. Biotechnol. 27, 892 (2009).

120. Sivasubramanian, A., Sircar, A., Chaudhury, S. \& Gray, J.J. Toward high-resolution homology modeling of antibody $\mathrm{Fv}$ regions and application to antibody-antigen docking. Proteins 74, 497-514 (2009).

121. Grosdidier, A., Zoete, V. \& Michielin, O. SwissDock, a protein-small molecule docking web service based on EADock DSS. Nucleic Acids Res. 39, W270-277 (2011).

122. de Villartay, J.P., Fischer, A. \& Durandy, A. The mechanisms of immune diversification and their disorders. Nat. Rev. Immunol. 3, 962-972 (2003).

123. Westra, E.R., Sunderhauf, D., Landsberger, M. \& Buckling, A. Mechanisms and consequences of diversity-generating immune strategies. Nat. Rev. Immunol. 17, 719728 (2017).

124. Benedict, C.L., Gilfillan, S., Thai, T.H. \& Kearney, J.F. Terminal deoxynucleotidyl transferase and repertoire development. Immunol. Rev. 175, 150-157 (2000).

125. Neuberger, M.S. Antibody diversification by somatic mutation: from Burnet onwards. Immunol. Cell. Biol. 86, 124-32 (2008).

126. Peled, J.U. et al. The biochemistry of somatic hypermutation. Annu. Rev. Immunol. 26, 481-511 (2008).

\section{Acknowledgments}

This work was supported by Institut National de la Santé et de la Recherche Médicale (INSERM, France) and European Research Council Starting Grant (Project CoBABATI ERC-StG-678905 to J.D.D.).

\section{Author contributions}

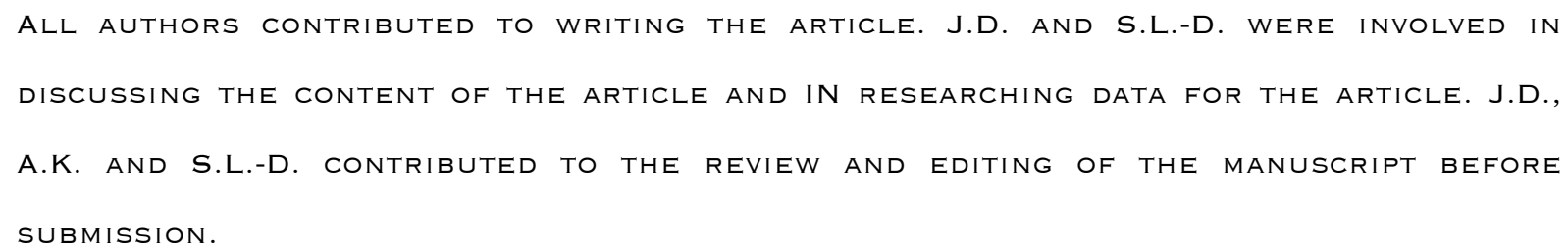




\section{Competing interests}

THE AUTHORS DECLARE NO COMPETING INTERESTS.

\section{Publisher's note}

SPRINGER NATURE REMAINS NEUTRAL WITH REgARD TO JURISDICTIONAL CLAIMS IN PUBLISHED MAPS AND INSTITUTIONAL AFFILIATIONS.

\section{Reviewer information}

Nature Reviews immunology thanks G. Alter, P. Wilson and the other anonymous REVIEWER(S) FOR THEIR CONTRIBUTION TO THE PEER REVIEW OF THIS WORK.

\section{BOX 1. Structural organization of the variable region of antibodies}

The variable $(\mathrm{V})$ region or $\mathrm{V}$ fragment $(\mathrm{Fv})$ of antibodies consists of two non-covalently linked Ig domains, that is the variable light chain (VL) and variable heavy chain (VH) domains. Each V domain contains approximately 120-130 amino acids and has the prototypic Ig superfamily domain structure of two antiparallel beta sheets. The beta-strands from the two different planes are connected by loops that usually lack secondary structure. A single disulphide bridge between conservative cysteine residues and multiple hydrophobic contacts are responsible for the maintenance of the fold of each $\mathrm{V}$ domain. The variability in amino acid sequence differs throughout the structure of the V domains. Thus, each domain has four relatively invariant parts referred to as framework regions (FR1-FR4) and three regions characterized by a high heterogeneity in the amino acid sequence referred to as complementarity determining regions (CDR1-CDR3). The CDRs overlap with three of the surface exposed loops that connect beta-strands at the tip of the $\mathrm{V}$ domains. The sequence variability among different CDR loops also differs, the CDR H3 and CDR L3 loops being the most diverse regions of the $\mathrm{V}$ domain. Moreover, the length of the CDR H3 loop markedly varies between different antibodies; lengths of CDR H3 ranging from 2 to $>30$ amino acids 
have been reported for human antibodies. Not surprisingly this region plays a central role in the binding to antigens. The association of VL and VH brings in close proximity the CDRs loops from the two Ig domains. The six CDR loops along with some parts of the FR comprise the antigen-binding site of the antibodies. The CDR3 regions of heavy and light V domains are localized at the center of the antigen-binding site. Besides their central role for binding to antigen, the CDRs are focal points for the incorporation of mutations during the process of affinity maturation. Accordingly, these parts of the V regions carry most of the modifications responsible for the unconventional diversification of antibody specificity.

\section{BOX 2. Conventional mechanisms for antibody diversification}

The diversity of antibody repertoires is principally generated by two genetic mechanisms that involve recombination and mutation of the immunoglobulin genes ${ }^{4,122,123}$. The process of $\mathrm{V}(\mathrm{D}) \mathrm{J}$ recombination contributes to the variability of the immune repertoires by introducing both combinatorial and junctional diversity in the $\mathrm{V}$ regions. The combinatorial diversity is based on the presence in the Ig gene locus of multiple gene segments encoding the variable regions of the heavy $\left(\mathrm{V}_{\mathrm{H}}\right)$ and light $\left(\mathrm{V}_{\mathrm{L}}\right)$ chains. An intact $\mathrm{V}_{\mathrm{H}}$ is encoded by an assembly of $\mathbf{V}$ (variable), D (diversity) and $\mathbf{J}$ (joining) gene segments. A stochastic recombination of the gene fragments can result in generation of $6210-7176$ possible sequences of $V_{H}$. The $V_{L}$ regions are encoded by two joined segments, that is V and J. It was estimated that humans can generate $280 \mathrm{V \kappa}$ and $145-165 \mathrm{~V} \lambda$ possible combinations ${ }^{4}$.

The junctional diversity considerably extends the heterogeneity of the $\mathrm{V}$ regions generated by the recombination process. The process overlaps temporally with V(D)J recombination during the early phases of B cell development. Upon recombination of gene segments, DNA processing enzymes add or delete nucleotides at the 3' and 5' extremities of the $\mathrm{V}, \mathrm{D}$ and $\mathrm{J}$ segments, thus introducing imprecise junctions. The enzyme terminal 
deoxynucleotidyl transferase is responsible for addition of so-called non-template encoded nucleotides ${ }^{4,124}$. Moreover, the opening of hairpin structures of DNA at the ends of the joining fragments can results in the insertion of short palindromic nucleotide sequences.

The second mechanism of diversification of the sequences of the $\mathrm{V}$ regions is based on the introduction of point mutations throughout the $\mathrm{V}_{\mathrm{H}}$ and $\mathrm{V}_{\mathrm{L}}$ regions ${ }^{125}$. This process usually takes place in secondary lymphoid organs after contact of naïve or memory B cells with antigens in the presence of antigen-specific helper $T$ cell. The enzyme activation-induced cytidine deaminase, which is unique to the $\mathrm{B}$ lymphocyte linage, is responsible for the introduction of the point mutations ${ }^{126}$. The process of somatic hypermutation markedly extends the sequence heterogeneity of the rearranged variable regions.

\section{Figure legends}

\section{Figure 1: Diversification of antibody specificity by incorporation of non- immunoglobulin sequences in the $\mathrm{V}$ region}

(A) Insertion of entire protein into the antigen-binding site. Certain antibodies that recognize Plasmodium sp. antigens integrate the protein leukocyte-associated immunoglobulin-like receptor 1 (LAIR1) into their $\mathrm{V}$ region. The modified binding site allows the antibodies to recognize repetitive interspersed families of polypeptides (RIFIN) antigens, thus contributing to the clearance of the infected cells. (B) Short nucleotide insertions and deletions (Indels). Antibodies generated as result of chronic infections with highly mutatable pathogens (such as HIV-1 and influenza virus) frequently have short sequence insertions or deletions in the CDR or framework region. These changes in the sequence cause reconfiguration of the antigenbinding site, which can facilitate the accommodation of not well accessible epitopes. The antigens are presented as shapes in dark blue. Right panels: side and top views of the structural representations of antibody MGD21 with LAIR1 insertion and of the broadly 
neutralizing HIV-1 antibody 3BNC60 with indel (created using PDB file 5NST ${ }^{11}$, and $3 \mathrm{RPI}^{117}$, respectively). The structural models were visualized by UCSF Chimera software package $^{118}$. Grey: Ig light chain; blue: Ig heavy chain; red: LAIR1 or Indel.

Figure 2. Diversification of antibody specificity through post-translational modifications in the antigen-binding site

(A) Tyrosine-sulphation. Certain HIV-1-neutralizing antibodies have the addition of sulphate groups to tyrosine residues present in their CDR H3. The sulphate groups enrich chemical diversity of the binding interface and directly contribute to the interaction with gp120. Removal of this post-translational modification is accompanied by lost or reduction of binding and virus-neutralization activities. Right panel: side and top views of the structural representation of the Fab of the HIV-1 neutralizing Ab 412d that contains two sulphotyrosines in CDR H3 (created using PDB file 2QAD ${ }^{26}$ ). Grey: Ig light chain; blue: Ig heavy chain; red: side chains of sulphated tyrosines. (B) Fab-glycosylation. A fraction of antibodies can carry N-linked glycan structure bound to CDR regions. The glycan structure is complex type and often terminates with sialic acid. Antibodies can utilize the carbohydrate moieties as a part of extended binding site, which allows establishment of specific interactions with antigen.

Figure. 3 Diversification of antibody specificity by conformational dynamics and reconfiguration of the antigen-binding site

(A) Conformational isomerism of antigen-binding site. Some antibodies have antigen-binding sites characterized by high structural plasticity. The malleable antigen-binding sites would allow an antibody to assume variety of configurations each apt for interaction with distinct antigen, thus resulting in diversification of the repertoire of recognized antigens. An antibody 
exists in various configurations (isomers) before encounter of antigen. The structural models depict the top views of the antigen-binding sites of two conformational isomers of Ab SPE-7 in the absence of the target antigens (PDB files 1OAQ and $10 C \mathrm{CW}^{68}$ ). Grey: VL domain; blue: VH domain. (B) Global rearrangement of the antigen-binding site. HIV-1 broadly neutralizing antibody-2G12 bind to glycans expressed on gp120. The binding site of this antibody has unusual structural organization, product of swapping of heavy chains from two arms of IgG molecule. Thus, 2G12 have a large flat binding surface that is sterically optimized for recognition of sugar residues from gp120. The structural model depicts the side and top views of the heavy chain domain-swept Fab of the broadly neutralizing HIV-1 Ab 2G12 (PDB file $6 \mathrm{~N} 32^{78}$ ). Grey: Ig light chain; blue: Ig heavy chain.

\section{Figure 4. Diversification of antibody specificity by use of cofactor molecules}

(A) Use of metal cofactors. Antibodies can bind $\mathrm{Ca}^{2+}$ ions using amino acid residues from the antigen-binding site. The metal ions are displayed at the binding surface and serve as a bridge for interaction with the target antigen. Absence of $\mathrm{Ca}^{2+}$ ions in the antigen-binding site results in abrogation of antigen binding or large (55000 folds) reduction in the binding affinity. The figure shows the side and top views of the structural model of the $\mathrm{V}$ region of the $\mathrm{Ca}^{2+}$ dependent Ab Q425 created using the PDB file 2ADG ${ }^{82}$. Grey: VL domain; blue: VH domain. The $\mathrm{Ca}^{2+}$ ion is displayed as a red sphere. (B) Diversification by use of haem. Some antibodies can interact with haem and use its unique chemical signature as a part of the antigen-binding interface. Haem is an inherently promiscuous molecule ${ }^{119}$ and can mediate considerable diversification of the antigen-binding specificities of the antibodies. The three dimensional structure of the haem-binding antibody (Ab21) was modeled by sequence-based $\mathrm{V}$ region modeling algorithm RosettaAntibody $3^{120}$ implemented on ROSIE web server 
(http://rosie.rosettacommons.org/). The putative haem-binding site was then predicted by docking the protoporphyrin IX molecule to the $\mathrm{V}$ region using the SwissDock web service based on EADock DSS ${ }^{121}$ (http://www.swissdock.ch/). The figure shows side and top view of the V domain of Ab21. Grey: VL domain; blue: VH domain. Haem is displayed in red.

\section{Figure 5. Different levels of diversification of antibody repertoires}

The figure depicts the three levels of generation of antigen-binding diversity in immune repertoires with respect to the theoretical set of all potential antigenic structures that immune system can encounter (referred to as 'Antigen space'). The variability of antibodies generated by combinatorial and junctional diversity is limited and covers a small area of the antigen space. The resulting repertoire of binding specificities is nevertheless sufficient to control a substantial array of pathogens by thymus-independent $B$ cell responses. Somatic hypermutations represent the second level of introduction of antibody diversity that occurs at the time of affinity maturation during thymus-dependent immune responses. The variability in antigen-binding specificity acquired by this process is sufficient for controlling most of pathogens. The third level of diversification of antibody specificities implicates additional unorthodox strategies for remodeling of $\mathrm{V}$ regions. These processes considerably extend the coverage of the antigen space. In particular, unorthodox, or unconventional, pathways for diversifications are typically summoned in cases of infections with pathogens with high antigen variability. We propose that the evolutionary pressure exerted by an ever-mutating pathogen on the immune system dictates the engagement of unconventional mechanisms for a further expansion of the array of antigen-binding specificities. Whether a synergy between the three levels of diversification is sufficient to cover entire antigen space remain unclear. 
Figure 1

a. Insertion of protein in $\mathrm{V}$ region
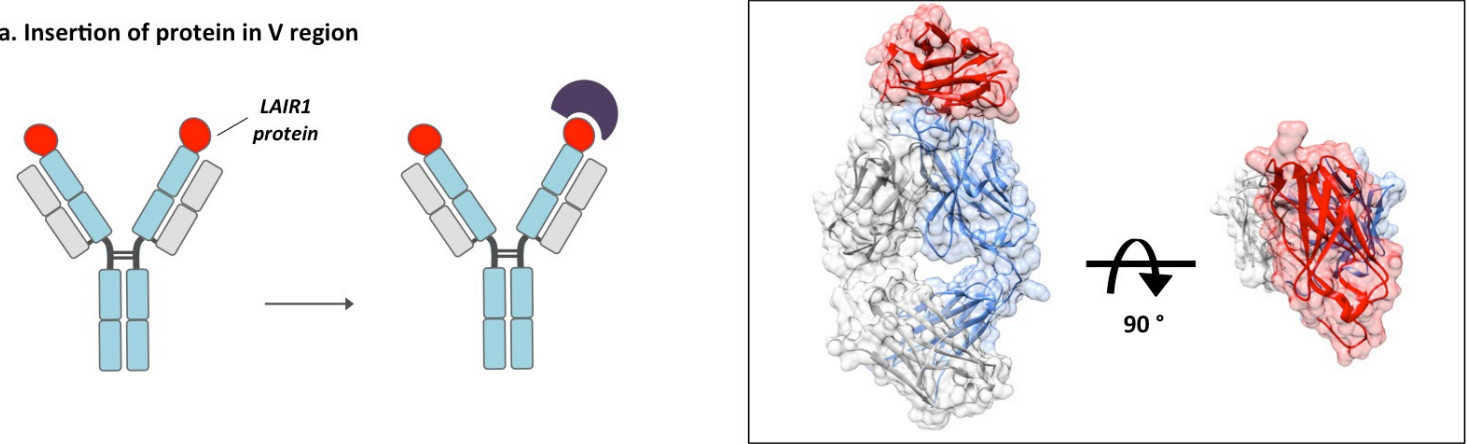

b. Insertion / deletion of short sequence in $\mathrm{V}$ region Indel
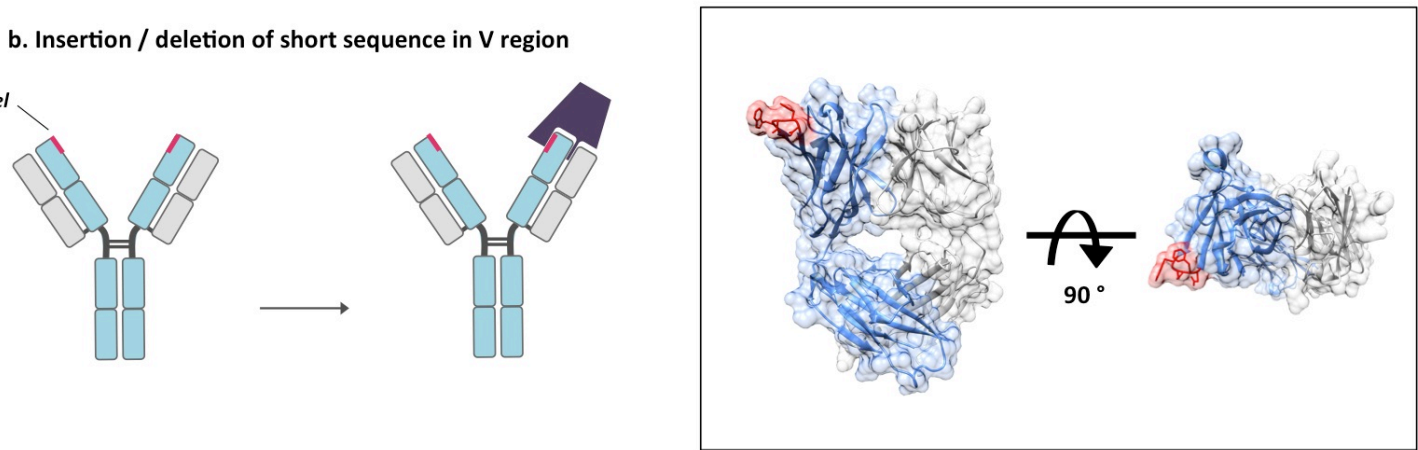
Figure 2

a. Tyrosine sulfation
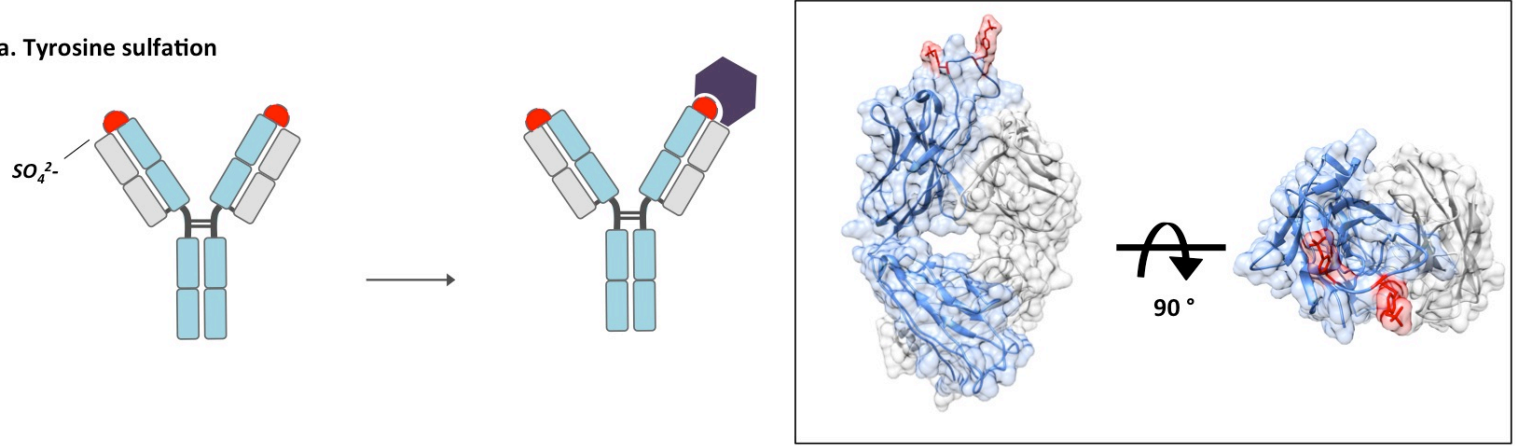

b. $\mathrm{V}$ region glycosilation

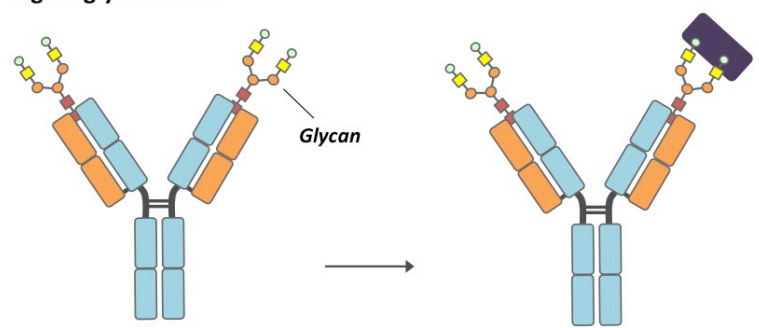


Figure 3

a. Conformational isomerism
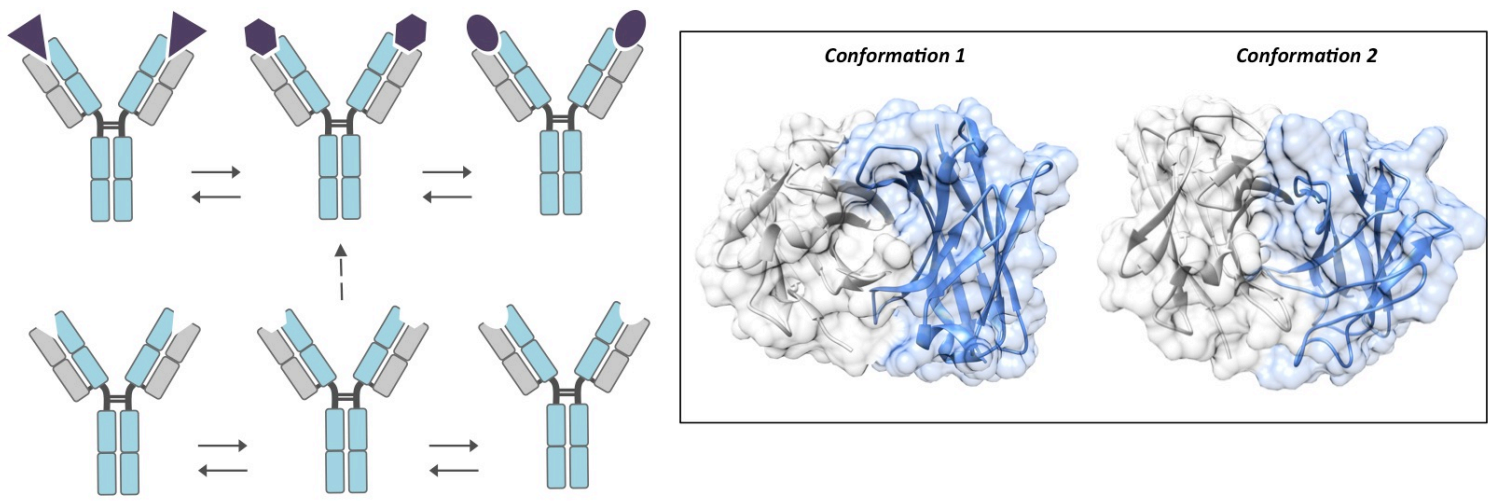

b. Reconfiguration of $\mathrm{V}$ region
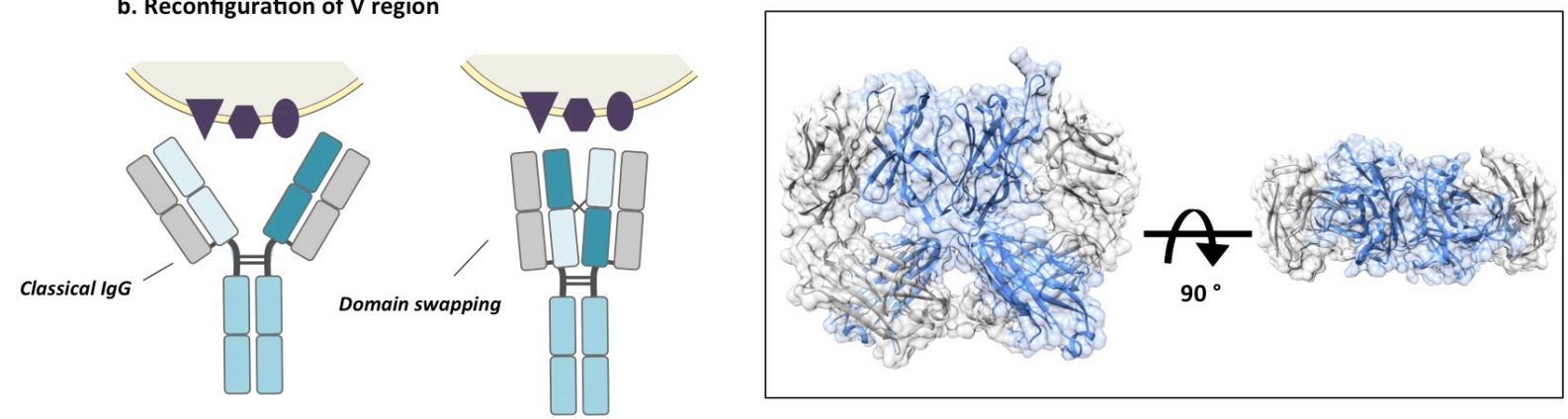
Figure 4

a. Use of metal ions

$\mathrm{Ca}^{2+}$

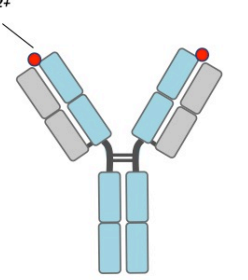

b. Use of heme

Heme

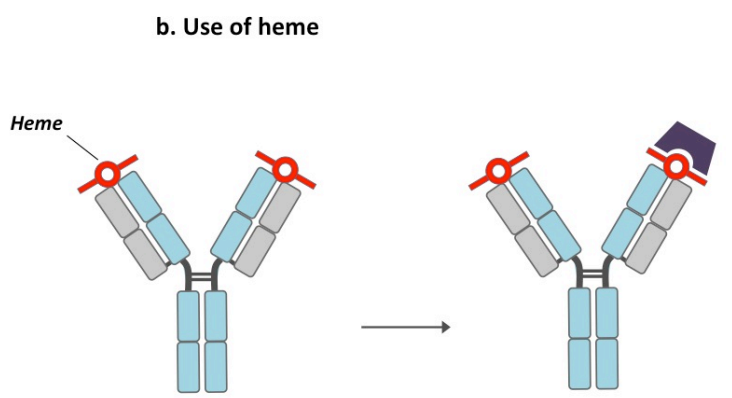

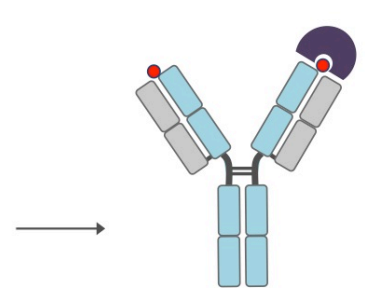

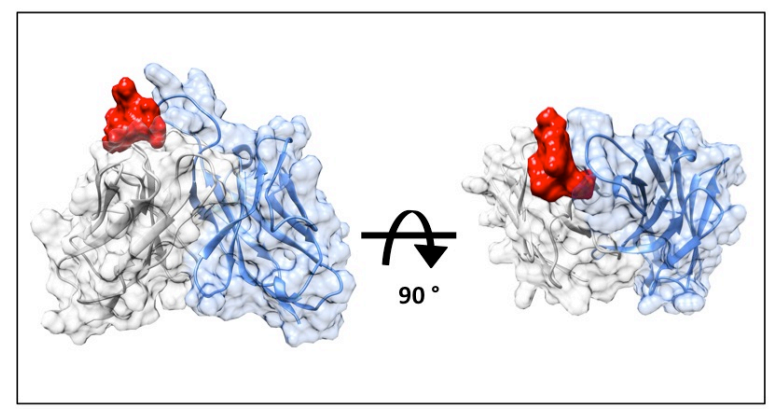


Figure 5

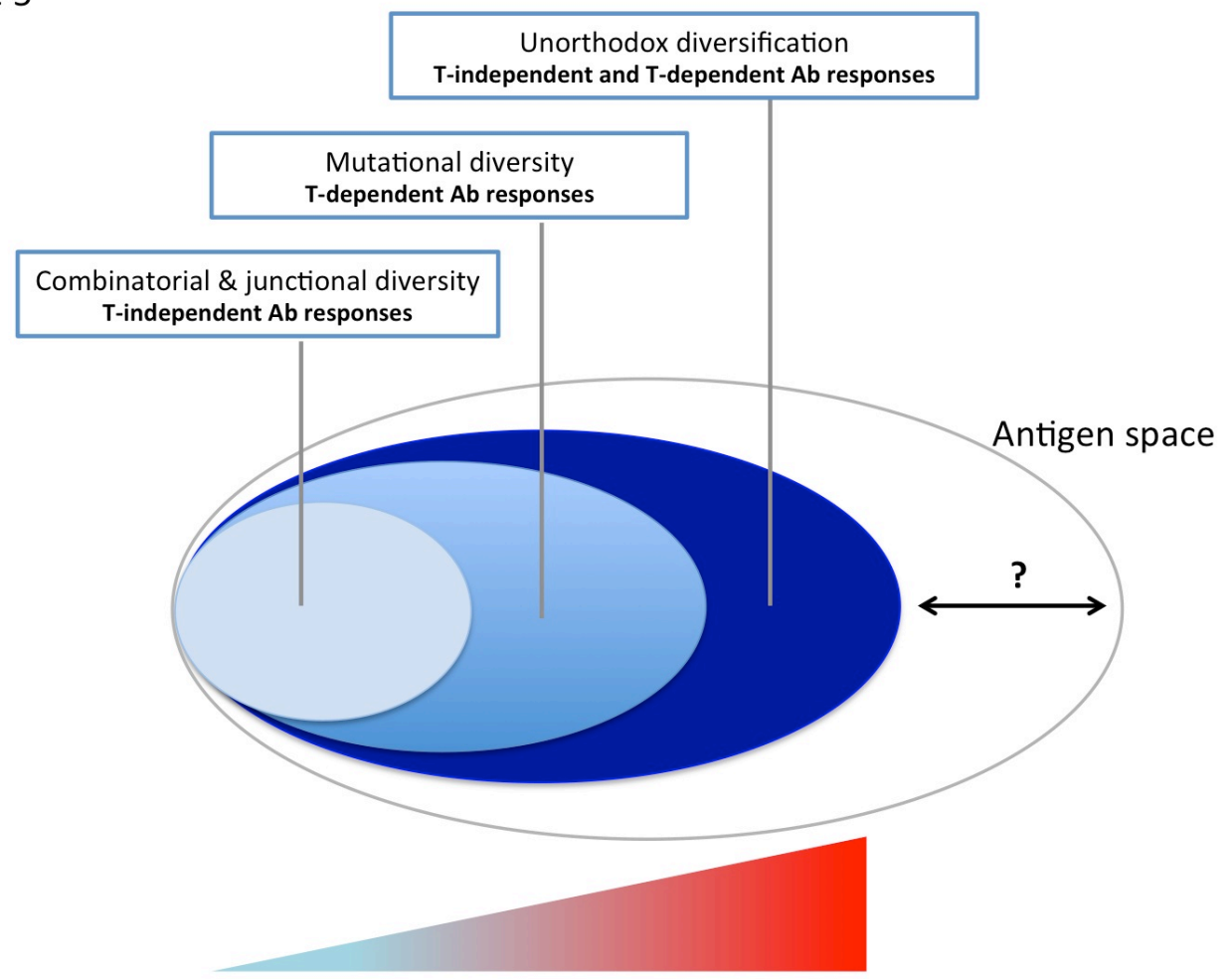

Immune evasion capacity of pathogens 
Figure BOX

Conventional mechanisms of generation of diversity of Igs

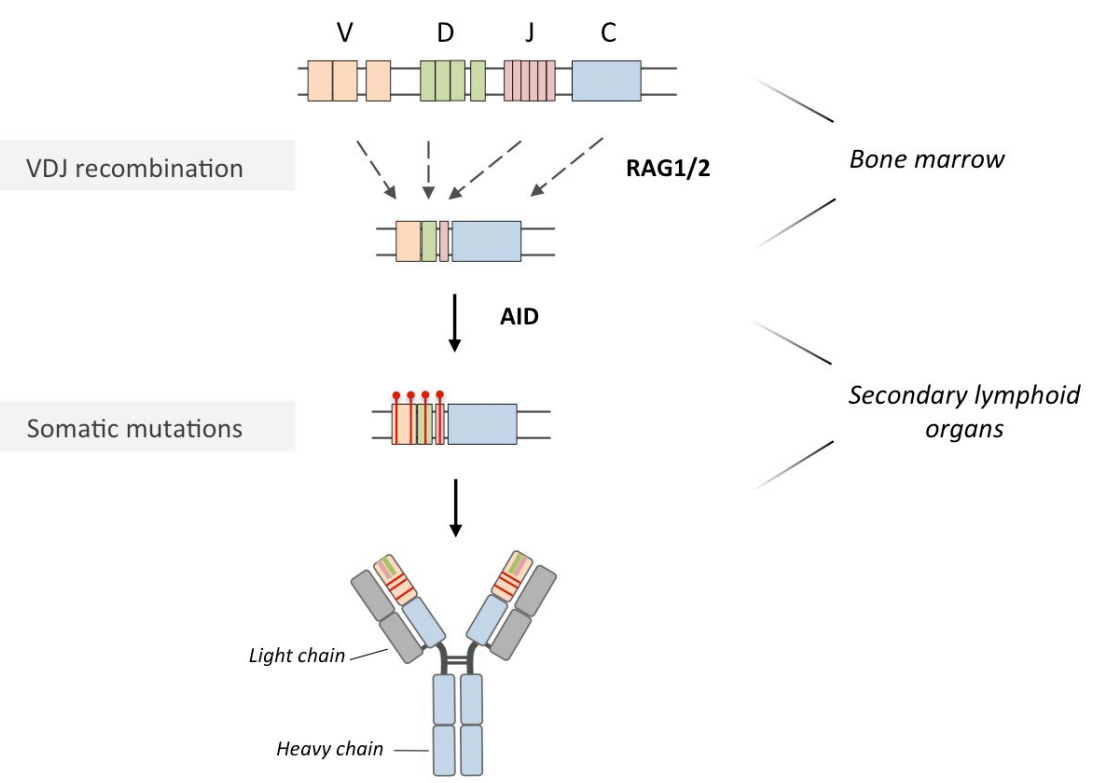

